\title{
Conditional Conservatism and the Cost of Equity Capital: Informational, Fundamental, and Behavioral Effects
}

\begin{abstract}
Conditional conservatism $(\mathrm{CON})$ is related to the cost of equity capital in a complex way, especially in imperfect markets. Prior literature suggests that CON affects the information precision and information asymmetry, resulting in either increased or decreased cost of equity. In addition, CON may influence firms' investment decisions and exacerbate their fundamental operating risks, and investors are asymmetrically loss-averse to more bad earnings news reporting via conservative disclosure, both of which contribute to a higher equity cost. This paper empirically examines the impact of $\mathrm{CON}$ on the cost of equity capital through these informational, fundamental and behavioral risk effects, and detects a significantly positive association between $\mathrm{CON}$ and equity cost by adopting accounting-based CON proxies and equity cost measures adjusted for unexpected cash flow shocks. Using the Sarbanes-Oxley Act (SOX) as a natural experiment, we find that the positive CON-equity cost relation disappears in the post-SOX period, consistent with diminished informational, operational, and behavioral risk effects engendered by SOX regulations.
\end{abstract}

Keywords: conditional conservatism; cost of equity capital; asset pricing tests; Sarbanes-Oxley $\operatorname{Act}(S O X)$.

JEL Classifications: $M 41 ; G 32 ; G 12 ; G 14$. 


\section{Introduction}

Conditional conservatism (CON hereafter) is a salient feature of financial reporting that reflects a firm's commitment to timely bad earnings news disclosure. ${ }^{1}$ CON's extensive economic impact on accounting information has been well-documented in the literature and is essential to the decision making of both investors and firm managers. CON's role in affecting firms' cost of equity capital, however, has not been well-established. This paper posits to empirically examine on the association between $\mathrm{CON}$ and the cost of equity and provide insights into how investors' and firms' reactions to conservative disclosure contribute to the CON-equity cost relation.

Prior studies suggest that one major channel through which CON affects firms' cost of equity capital is information risk, including information quality (or precision) and information asymmetry, with general consensus that better information quality and less information asymmetry decrease firms' cost of capital, ceteris paribus. A strand of analytical research demonstrates that accounting conservatism improves the overall quality of information via providing more accurate signal to mitigate the payoff loss due to conservative bias (Fan and Zhang 2011), alleviating dysfunctional earnings manipulation (Chen et al. 2007), limiting the probability of bad firms obtaining high signals and reducing their free-riding benefits (Nan and Wen 2011), or encouraging full disclosure through more voluntarily convey of timely good news (Guay and Verrecchia 2007). There is, however, no unanimous agreement regarding the information asymmetry effect of accounting conservatism. Some studies do not specifically differentiate information asymmetry and information quality (e.g., Diamond and Verrecchia

\footnotetext{
${ }^{1}$ As guidance, the FASB's Statement of Financial Accounting Concepts No. 2 (1980, para. 95) intones that "if two estimates of amounts to be received or paid in the future are about equally likely, conservatism dictates using the less optimistic estimate." The Accounting Principles Board (Statement No. 4 1970, para. 171) observes that "managers, investors, and accountants have generally preferred that possible errors in measurement be in the direction of understatement rather than overstatement of net income and net assets. This has led to the convention of conservatism."
} 
1991), or assume better quality disclosure reduces information asymmetry via decreasing the information advantage of sophisticated investors (Botosan 2006; Francis et al. 2004), or argue more disclosure improves risk-sharing across generations of investors (Suijs 2008). In contrast, other studies including Gow et al. (2011) and Lambert et al. (2012) suggest that publicly reported earnings information is a complement to the private information held by sophisticated investors, and a more precise disclosure may increase heterogeneity of opinions among market participants and make them more dissimilarly informed, thus enhancing information asymmetry. This is consistent with the evidence from Biddle et al. (2011) that loan charge-offs mandated by impairment rules increase a financial firm's contribution to systemic risk by elevating information asymmetry among mangers and stakeholders of other banks and Haggard et al. (2011) that large asset write-downs also increase information asymmetry.

Therefore, how CON affects equity cost through the information channel results from the combined influence of information precision and information asymmetry. The two effects, however, play different roles in different settings. In classical competitive noisy rational expectations economy, there is no cross-sectional effect of information asymmetry on cost of capital, implying that only average information quality (precision) can be priced by the investors (Hughes et al. 2007; Lambert et al. 2012). ${ }^{2}$ On the other hand, when competition is imperfect and markets are illiquid, asymmetric information can significantly affect the cost of capital even after controlling for information precision (Lambert et al. 2012, Lambert and Verrecchia 2010). This argument is supported by empirical findings from Akins et al. (2011), Armstrong et al. (2011), and Gow et al. (2011) who establish that information asymmetry can affect incrementally

\footnotetext{
${ }^{2}$ For example, Hughes et al. (2007) indicate that the pricing of asymmetric information as claimed by Easley and O'Hara (2004) in a competitive market is a "misperception" and only information asymmetry about systematic factors affects factor (market-wide) risk premiums.
} 
firms' cost of capital when the market for the firms' shares is less than perfectly competitive. ${ }^{3}$ The above analyses and evidence suggest that CON may be associated with a lower cost of equity by increasing the information precision and thus decreasing total information risk when markets are efficient with perfect competition and liquidity, since in such markets there is no information asymmetry effect. When markets are not perfect, which is likely in practice, if the more precise earnings information via conservative disclosure attenuates information asymmetry, the cost of equity will be further reduced; if earning precision exacerbates information asymmetry, then more asymmetric information leads to higher cost of equity which offsets the lower equity cost due to improved information quality, with the combined effect undetermined analytically.

Conservative disclosure not only affects investors' decision making through the information channel, but also influence firms' production or investment efficiency, and thus fundamental operational risk, with less efficiency and more fundamental risk being associated with higher cost of equity. Analytically, Gao (2010) demonstrates that disclosure quality (via CON) could increase cost of capital when new investment is sufficiently elastic via increasing the overall risk of firms' cash flow. Gao and Liang (2011) show that the "leveled play field" by more disclosure (e.g., more public information from conservative reporting) impedes firms' investment efficiency via dampening information producing by speculators in the market. ${ }^{4}$ Similarly, Lambert et al. (2007) suggest that higher quality disclosures from CON affect a firm's real decisions with respect to production or investment, which further change the impact of expected cash flow on

\footnotetext{
${ }^{3}$ Akins et al. (2011), Armstrong et al. (2011), and Gow et al. (2011) also find information asymmetry does not affect the cost of equity incremental to market risk if firms' stocks are traded in highly liquid and competitive markets.

4 Gao and Liang's (2011) model is developed from Grossman and Stiglitz (1980) who demonstrate that "there is a fundamental conflict between the efficiency with which markets spread information and the incentives to acquire information." The intuition is that more disclosure discourages private information acquisition by speculators, and the speculators' information set is not a subset of the firm's and is reflected via asset prices. Preemptive disclosure thus reduces stock price informativeness to the firm, leading to misallocation of resources and investment inefficiency.
} 
covariance risk and hence influence the firm's cost of capital. If improved information quality makes managers more aggressive in investment choice, the resulting misallocation (i.e., inefficiency) may cause a higher equity cost. Conditional conservatism also more directly affects cost of equity via revised perceptions of risk embedded in firms' fundamentals. CON induces reported earnings numbers to timely reflect more pessimistic estimates, which increases earnings downside risk and enhances its ability to capture fundamental operating risk. As empirically shown by Luo et al. (2011), higher earnings downside risk (especially accrual downside risk) is associated with higher cost of equity capital (stock's expected returns). Thus, conditional conservatism may affect the cost of equity capital by indirectly influencing firms' real investment decisions and directly conveying downside risk inherent in firms' operations.

In imperfect markets, conditional conservatism may further affect cost of equity by engendering behaviorally-motivated mispricing. As advocated by FASB's Statement of Financial Accounting Concepts No. 2 (1980, para. 95), one major function of CON is to convey bad earnings news in a timely manner. By conception, CON reports income-decreasing events with a downward bias, i.e., earnings losses are revealed with larger magnitude and more frequency than the true economic earnings. With the existence of information inefficiency, investors may have asymmetrically stronger reactions to bad earnings news conveyed by conditional conservatism than to good news, exhibiting loss aversion as suggested by Roy (1952), Kahneman and Tversky (1979), and Veronesi (1999). Such an effect can be further enhanced as frequent biased loss reporting induces investors to face more ambiguity and adopt shorter horizons, thus heightening the ambiguity aversion (Epstein and Schneider 2008) and myopic loss aversion (Benartzi and Thaler 1985). These behavioral influences lead to a higher perceived risk by investors which causes them to require a higher compensation when providing equity funds, 
i.e., an increased cost of equity to the firm.

In summary, literature suggests that conditional conservatism is related to the cost of equity capital in a complex way, especially in imperfect markets where the information asymmetry, fundamental operational risk, and behavioral influences may add an equity cost increasing effect which counterbalances the cost decreasing effect of improved information quality by CON, leaving the overall CON-equity cost relation an empirical issue. Existing empirical studies on this issue, however, are limited and mostly conducted under implicit assumption of efficient market, i.e., assuming equity price reflects all publicly available information correctly and in a timely manner. For example, using stock price's asymmetric response to good and bad earnings news as a proxy for conditional conservatism (Basu 1997), Francis et al. (2004) find that CON has no significant association with the cost of equity. Lara et al. (2011) construct a conditional conservatism measure within the framework of Callen et al. (2010), which is also a market price-based conservatism metric, and show that it significantly reduces cost of equity capital. Both studies explain the findings from the perspective of information risk, i.e., CON induces less uncertainty in information which lowers the equity cost. This is mainly an information quality (precision) effect as demonstrated above. The effects of information asymmetry, investor loss aversion, and fundamental operation risk, however, are largely constrained in the frameworks of these studies (i.e., the adopted CON measures are designed under the assumption of informationally efficient market with perfect competition implication). ${ }^{5}$ Since all these three effects have the potential to increase equity cost, the cost of equity capital for firms with more conservative reporting may become higher if the influences from information asymmetry, investor behavior, and fundamental risk are considered, which, if strong enough, may even

\footnotetext{
${ }^{5}$ Other market-based CON measures, for example, the C-score in Khan and Watts (2008), also have the same implicit assumption of market efficiency and competition perfection.
} 
dominate the information precision effect and result in a positive $\mathrm{CON}$-equity cost relation. However, no study has explicitly examined this issue so far in the literature.

This paper is thus motivated to investigate the relation between conditional conservatism and the cost of equity capital through the abovementioned information asymmetry, behavioral, and fundamental effects, which represent the aspects of conditional conservatism that may potentially increase equity cost. To this end, we must relax the market efficiency and perfect competition assumption. This implies that it is necessary to disentangle the conditional conservatism and cost of capital measures from the impacts of stock market information and cash flow shocks since we no longer assume market price is a timely and correct reflection of good or bad earnings news revealed by CON. For example, equity price observed in imperfect markets may have endogenously incorporated the effects of information risk (especially information asymmetry), its feedback on firms' investment and fundamental operations, and potential mispricing. In order to examine how conditional conservatism influences the cost of equity through these effects, the CON measure has to be free from using market-based data to avoid mechanically induced endogeneity problem. Therefore, in this study, we employ accounting information to construct a proxy for conditional conservatism as the average of accumulated non-operational accrual and relative earnings skewness, following Givoly and Hyan (2000) and Zhang (2008). This accounting-based measure more directly reflects bad news conveyed to market participants by conditionally conservative disclosure which helps provide clearer inferences not only regarding the information asymmetry and behavioral effects driven by market activities, but also about the operational risk effects driven by firms' fundamentals. With the same spirit, we control for the effect of cash flow shocks on estimated equity cost since conservative treatment like large accrual expense (which increases CON measure) may at the 
same time reflect unexpected negative shocks to future cash flows (which decrease the realized stock returns), resulting in a noisy cost of equity measure and a potential mechanical negative relation between $\mathrm{CON}$ and equity cost. To factor out the disturbance of unexpected cash flow shocks, we adopt an ex ante cost of equity capital measure as realized excess return adjusted for cash flow news, as suggested by Vuolteenaho (2002), McInnis (2010), Ogneva (2010), and Botosan et al (2011). ${ }^{6}$

We conduct empirical examinations on the relation between accounting-based conditional conservatism measure and cash flow news adjusted cost of equity proxy by utilizing standard asset pricing tests that include hedging portfolio analyses and multivariate regressions, while controlling for industry effects as suggested by Lewellen et al. (2010). Using a sample of 62,833 U.S. firm-year observations for the period of January 1986 to December 2008, we document a significant positive relation between conditional conservatism and cost of equity capital, suggesting the equity cost enhancing effects of conditional conservatism generated from information asymmetry, investor loss aversion, and higher fundamental downside risk exhibit a dominating power in influencing firms' cost of equity. In particular, a hedging strategy for CON-sorted portfolios earns significantly positive cash flow new adjusted excess returns. Firm level Fama-MacBeth cross-sectional regressions yield significantly positive associations between conditional conservatism and future excess returns adjusted for cash flow news, with and without controlling for firm risk characteristics. Portfolio level two-stage cross-sectional regressions reveal conservatism factor loadings to be significantly positively associated with return spreads for $\mathrm{CON}$-sorted portfolios, implying that conditional conservatism is priced by market participants.

\footnotetext{
${ }^{6}$ Botosan et al. (2011) and Ogneva (2010) argue that cash flow news does not cancel out in large samples, thus asset pricing tests may induce biases when future realized returns are used to proxy for expected returns.
} 
We present supporting evidence regarding the information asymmetry, behavioral, and fundamental downside risk effects on the relation between conditional conservatism and cost of equity. Portfolio analyses indicate that larger $\mathrm{CON}$ is generally associated with higher information asymmetry and higher earnings downside risk. Controlling for information asymmetry and/or earnings downside risk in Fama-MacBeth regressions substantially reduces the coefficients for CON, i.e., information asymmetry and fundamental downside risk largely subsume the positive CON-equity cost relation. Hedging portfolio analyses reveal that significantly positive returns to $\mathrm{CON}$ are more prominent for higher $\mathrm{CON}$ portfolios, not affected by firm size, book-to-market ratio, and total accruals, and do not concentrate in any single year. These findings suggest that behavioral-based mispricing also contributes to the positive relation between CON and equity capital cost, which is partially caused by overreaction to bad earnings news and supports the loss-aversion argument.

The passage of the Sarbanes-Oxley Act of 2002 (SOX) offers a nature experiment for investigating the three abovementioned influences on $\mathrm{CON}$-equity cost relation. SOX regulations were promulgated to increase financial reporting transparency, reduce information asymmetry, and improve market efficiency. Combined with effects of dampened risk-taking and constrained level of capital which decreases firms' operational risk (Kang et al. 2010; Bargeron et al. 2010), we argue that SOX should have mitigated information asymmetry, behavioral, and fundamental downside risk influences of conditional conservatism on the cost of equity capital, despite a previously documented enhanced conditional conservatism following the enactment of SOX (e.g., Lobo and Zhou 2006; Biddle et al. 2011). To test this conjecture, we examine Fama-MacBeth regressions before and after SOX was enacted, and find confirming evidence that the positive association between CON and cost of equity capital disappears in the post-SOX period. The 
finding suggests that the positive CON-equity cost relation detected in the pre-SOX period is mainly driven by the information asymmetry, fundamental risk, and behavioral effects.

This study contributes to the literatures on accounting conservatism, equity capital cost, and SOX, and holds potential policy implications. We provide a comprehensive description on the influences of conditional conservatism on equity cost from the perspectives of informational, behavioral, and fundamental risk in markets of inefficient information and imperfect competition. We utilize conditional conservatism and cost of equity measures net of the influence of market information and unexpected cash flow shocks. Our finding of a positive relation between conditional conservatism and cost of equity capital supplements prior evidence of negative or insignificant CON-equity cost associations and delivers a more complete presentation of conditional conservatism's impact on firms' cost of equity. This paper also confirms that SOX produced structural changes in the association between conditional conservatism and equity cost, consistent with its intended mitigation of information asymmetry and improved market efficiency. Evidence documented in this study further helps inform deliberations regarding the economic influence of accounting conservatism, which the FASB and IASB recently removed as a fundamental characteristic of financial information in favor of neutrality.

We proceed as follows. Section II explains measures used for key variables and research design. Section III reports main asset pricing test results. Section IV tests separately the influences of information asymmetry, behavioral mispricing, and earnings downside risk. Section $\mathrm{V}$ examines associations between conditional conservatism and equity costs before and after the implementation of SOX. Section VI reports robustness checks. Section VII concludes.

\section{Measurement and Research Methodology}

We examine the relation between conditional conservatism and cost of equity capital under 
an imperfect market setting and from the perspectives of informational, fundamental, and behavioral influences. Ideally, the conditional conservatism measure should be free of the confounding impacts of stock market information, and the realized equity return as proxy for $e x$ anti cost of equity should be net of unexpected cash flow shocks, as both cases could induce spurious associations and biased inferences. In particular, a qualified CON measure in this context should not endogenously incorporate the firm's stock return which already incorporates effects of information asymmetry and its feedback to firms' investment and investors' behavior, especially when cost of equity is measured using equity return, otherwise a potential mechanical relation may result by construction. For the same reason, it is important to control for unexpected cash flow shocks (cash flow news) embedded in realized equity returns to measure investors' expected return for equity investment (i.e., firms' cost of equity). Prior evidence suggests that conditional conservatism is closely related to cash flow news (e.g., Callen et al. 2010; Kim and Pevzner 2010; Biddle et al. 2011b) that is compounded into stock prices. ${ }^{7}$ Cash flow news may also subsume private information feedback effects (Gao and Liang 2011) and increase information asymmetry (Gow et al. 2011). Therefore, asset pricing tests without controlling for cash flow news may yield spurious results about the impact of conservatism on cost of capital.

To facilitate our analyses, we measure cost of equity using realized excess returns that explicitly control for cash flow news and employ accounting-based conditional conservatism measures that are free from market information. Both treatments are amendable to our research purpose of a comprehensive examination about CON's influence on firms' equity cost under inefficient and noncompetitive market conditions, which allows for the functions of information

\footnotetext{
7 Callen et al. (2010) develop CR ratio, a market-based conservatism measure from the relation between conditional conservatism and cash flow news. Kim and Pevzner (2010) provide evidence that higher conditional conservatism is associated with lower probability of future bad cash flow news. Biddle et al. (2011b) similarly find that conditional conservatism increases OCF upside potential and thus the probability of good cash flow news.
} 
asymmetry, fundamental risk, and investors' behaviors in addition to the information precision effect documented in prior studies. In this sense, our measures are supplements rather than substitutes for existing proxies for conditional conservatism and equity cost.

\section{Conditional Conservatism Measure}

In the main tests, our accounting-based conditional conservatism measure $C O N$ equals the average of accumulated non-operational accruals $\left(C O N \_A c m\right)$ and negative earnings skewness (CON_Skew) which are defined as follows:

CON_Acm is defined as negative one times the ratio of accumulated non-operating accruals to accumulated total assets, with both computed using a rolling average of current and prior two years for each firm-year observation, and

Nonoperating accruals $=$ Total accruals $-\Delta$ accounts receivable $($ Compustat $R E C T)$

- Ainventories (Compustat INVT) - Aprepaid expenses (Compustat XPP)

+ Aaccounts payable (Compustat AP) + Ataxes payable (Compustat TXT)

This measure follows Givoly and Hayn (2000) and Biddle et al. (2011a, 2011b) and captures bad earnings news reporting via non-operational accruals, e.g., those arising from restructuring charges and asset write-downs.

CON_Skew is defined as negative one times the ratio of the sum of ten and earnings skewness to the sum of ten and the skewness of OCF, where skewness is estimated using a rolling window of 20 quarters of earnings and OCF, with minimum requirement for 12 quarters of data. This measure derives from Givoly and Hayn (2000) and adapts the negative skewness measure in Zhang (2008) to ensure that higher skewness indicates a higher degree of conditional conservatism. We deflate earnings skewness by OCF skewness to control for the influence of shocks in cash flow. 
Since $C O N \_A c m$ and $C O N \_S k e w$ are both noisy proxies for conditional conservatism and may capture non-conservatism elements such as big-baths, we use their average $C O N$ to help mitigate potential measurement errors. In later robustness tests, we examine $C O N \_A c m$ and CON_Skew seperately. We also employ negative earnings skewness Skew, defined as the difference between the skewness of OCF and earnings estimated over a rolling window of 20 quarters (Callen et al. 2010), and the average of Skew and CON_Acm as alternative conditional conservatism measures.

\section{Cost of Equity Measure}

Our cost of equity measures control for the effect of cash flow news by subtracting it from future realized excess returns, extending the methodology in McInnis (2010) and Ogneva (2010). ${ }^{8}$ Specifically, we calculate cash flow news (Ne) as follows: First, we estimate earnings surprises $(S U R P)$ from a time-series earnings prediction model augmented by economic determinants of earnings, assuming that annual earnings for firm $i$ follow an AR (1) process. We use a rolling window of five years to fit model (2) below by Fama and French (1997) industry classifications:

$E A R N_{i t+1}=\beta_{0}+\beta_{1} E A R N_{i t}+\beta_{2} S A L E_{i t}+\beta_{3} S I Z E_{i t}+\varepsilon_{i t+1}$

where $\operatorname{EARN}_{i t+1}\left(E A R N_{i t}\right)$ is earnings over book equity for the next (current) fiscal year, $S A L E_{i t}$ is sales over book value of total assets for the current fiscal year, and $S I Z E_{i t}$ is firm size measured as the natural logarithm of market equity at the current fiscal year-end.

Earnings surprise $S U R P_{i t+1}$ is then calculated as the difference between the actual and predicted $E A R N$ times the book value of equity, scaled by the beginning-of-month market value of equity. We obtain cash flow news from monthly cross-sectional regressions of excess stock

\footnotetext{
${ }^{8}$ Another measure for cash flow news is earnings forecast error (Botosan et al. 2011; Ogneva 2010), which is not used in our main tests since earnings forecast bias introduces further estimation bias. However, in robustness checks, we use it as alternative proxy for cash flow news with similar results.
} 
returns on contemporaneous earnings surprises using a linear OLS specification. Cash flow news $\left(N e_{i t+1}\right)$ is calculated as the product of $S U R P_{i t+1}$ and its estimated coefficient from the following models:

$R^{r a w}{ }_{i t+1}=\alpha_{0}+\alpha_{1} S U R P_{i t+1}+\varepsilon_{i t+1}$

$N e_{i t+1} \quad=\dot{\alpha}_{1} S U R P_{i t+1}$

where $R^{\text {raw }}$ is monthly excess return, $\dot{\alpha}_{l}$ is the estimated $\alpha_{l}$ in model (3). We use the next month's excess return adjusted for cash flow news $R_{i t+l}$ as the cost of equity capital proxy, i.e., $R_{i t+l}=\alpha_{0}$ $+\varepsilon_{i t+1}=R^{r a w}{ }_{i t+1}-N e_{i t+1}$.

\section{Information Asymmetry and Fundamental Risk Measures}

We use three measures for information asymmetry: the average daily percentage bid-ask spread IRisk, the average daily high and low spread HLSpread, and private information trading Itrade, with definitions given below:

IRisk: the average daily percentage bid-ask spread over the 12 months prior to the current fiscal year-end.

HLSpread: the average daily high and low spread over the 12 months prior to the current fiscal year-end, calculated following Corwin and Schultz (2011).

Itrade: private information trading estimated as in Llorente et al. (2002) and Ferreira and Laux (2007).

IRisk and HLSpread reflect information asymmetry in general, while Itrade denotes information asymmetry arising from speculators' information hunting. We use IRisk in the main tests and employ HLSpread and Itrade in robustness checks.

We adopt the following downside risk measures to capture fundamental risk in firms' operation, following Luo et al. (2011): 
ERisk: the root lower partial moment of total accruals calculated as the natural logarithm of the ratio of one plus the accrual root lower partial moment over one plus the accrual root upper partial moment. ${ }^{9}$

AERisk: the root lower partial moment of earnings over total assets (ROA) calculated as the natural logarithm of the ratio of one plus the root lower partial moment of ROA over one plus the accrual root upper partial moment of ROA.

Since accrual-based downside risk ERisk is the main source of earnings downside risk and drives its relation with cost of capital (Luo et al. 2011), we use ERisk in our main tests and AERisk in robustness checks.

\section{Asset Pricing Methodology}

Our main approach to examining the relation between conditional conservatism and cost of equity capital follows standard asset pricing methods including hedging portfolio analysis, Fama-MacBeth cross-sectional regression, and two-stage cross-sectional regression (2SCSR) analysis, as elaborated below. We also employ other approaches such as pooled OLS regression in robustness checks.

\section{Hedging Portfolio Analysis}

We first use a hedging portfolio approach that buys (sells) stocks with high (low) conditional conservatism measures to assess the association of conditional conservatism with cost of equity (cash flow news adjusted excess equity returns). ${ }^{10}$ Specifically, for each month, stocks are assigned to one of five portfolios based on a firm's most recent CON, with at least four months lag, with portfolio 1 (5) containing firms with the lowest (highest) level of CON.

\footnotetext{
9 See Luo et al. (2011) for estimation details. We utilize accrual downside risk because it is the source of earnings downside risk and has better prediction power for fundamental operational risk (Luo et al. 2011).

${ }^{10}$ Henceforth, we use the terms return or equity return to represent the excess returns adjusted for cash flow news, provided that no confusion arises.
} 
Monthly return difference between the highest (portfolio 5) and lowest (portfolio 1) CON portfolios is computed with a significant positive (negative) mean difference indicating a positive (negative) relation between $\mathrm{CON}$ and cost of equity capital.

Firm-Level Fama-MacBeth Cross-Sectional Regression

To control for other factors that may influence the CON-return relation, we regress firm-specific excess returns adjusted for cash flow news on CON and other firm characteristics. We match annual CON estimates with monthly returns in the next 12 months starting four months after the fiscal year-end. For example, for firms with fiscal year $t$ ending on December, we collect monthly returns data from April of calendar year $t+1$ to March of calendar year $t+2$. The following cross-sectional regression models are estimated monthly, and the coefficient parameters are averaged following the procedures in Fama and MacBeth (1973):

$$
\begin{aligned}
& R_{i t+1}-R_{F t+1}=\alpha+\beta_{1} C O N_{i t}+\mu_{i t} \\
& R_{i t+1}-R_{F t+l}=\alpha+\beta_{1} \operatorname{CON}_{i t}+\beta_{2} \text { Beta }_{i t}+\beta_{3} \text { Size }_{i t}+\beta_{4} B M_{i t}+\mu_{i t} \\
& R_{i t+1}-R_{F t+1}=\alpha+\beta_{1} \text {CON }_{i t}+\beta_{2} \text { Beta }_{i t}+\beta_{3} \text { Size }_{i t}+\beta_{4} B M_{i t}+\beta_{5} \text { Momentum }_{i t}+\mu_{i t} \\
& R_{i t+1}-R_{F t+1}=\alpha+\beta_{1} C O N_{i t}+\beta_{2} \text { Beta }_{i t}+\beta_{3} \operatorname{Size}_{i t}+\beta_{4} B M_{i t}+\beta_{5} T C A_{i t}+\mu_{i t} \\
& R_{i t+1}-R_{F t+1}=\alpha+\beta_{1} \text { CON }_{i t}+\beta_{2} \text { Beta }_{i t}+\beta_{3} \text { Size }_{i t}+\beta_{4} B M_{i t}+\beta_{5} \text { Acc }_{i t}+\beta_{6} \text { Low_Priced }_{i t}+\mu_{i t} \\
& R_{i t+1}-R_{F t+l}=\alpha+\beta_{1} \operatorname{CON}_{i t}+\beta_{2} \text { Beta }_{i t}+\beta_{3} \text { Size }_{i t}+\beta_{4} \text { BM }_{i t}+\beta_{5} \text { Momentum }_{i t}+\beta_{6} \text { TCA }_{i t} \\
& +\beta_{7} \text { Acc }_{i t}+\beta_{8} \text { Low_Priced }_{i t}+\mu_{i t}
\end{aligned}
$$

with variables defined as:

$C O N_{i t}=$ conditional conservatism measure for stock $i$ in month $t$,

$R_{i t+1}=$ monthly return adjusted for cash flow news for stock $i$ in month $t+1$,

$R_{F t+1}=$ the U.S. one-month T-bill rate in month $t+1$,

$B e t a_{i t}=$ beta of stock $i$ for month $t$ estimated as in Fama and French (1992), 
Size $_{i t}=$ the natural logarithm of market capitalization for stock $i$ in month $t$ as in Fama and French (1992),

$B M_{i t}=$ the natural logarithm of the ratio of book to market equity for stock $i$ in month $t$ as in Fama and French (1992),

Momentum $_{i t}=$ the buy-and-hold return of stock $i$ for the 11-month period ending one-month prior to the current month $t$, $T C A_{i t}=$ total accrual measured in the balance sheet approach scaled by total asset, following Sloan (1996), ${ }^{11}$ $A c c_{i t}=$ the decile ranking of accrual quality from Kim and Qi (2010) and Ogneva (2010), ${ }^{12}$ Low_Priced $_{i t}=$ the indicator variable for returns with two adjacent prices of less than five U.S. dollars as defined in Kim and Qi (2010).

Among the control variables, Beta, Size, and BM are commonly accepted factors that affect expected stock return. We include Momentum to ensure that the results are not attributable to conservative firms with previous negative returns. Since one $C O N$ component $\left(C O N \_A c m\right)$ is accrual-based, we control for $T C A$ and $A c c$ to ensure that the relation between conditional conservatism and equity return is robust to the pricing effects of TCA and Acc (Khan 2008; Ogneva 2010; Kim and Qi 2010). Low_Priced is also controlled along with Acc since penny stocks substantially impact Acc's pricing (Kim and Qi 2010). Following Lewellen et al. (2010), we include industry dummies in cross-sectional regressions to address the concern that missing industry effects may bias the coefficient estimates.

\footnotetext{
${ }^{11} T C A_{i t}=\left(\Delta C A_{i t}-\triangle C L_{i t}-\Delta C a s h_{i t}+\triangle S T D E B T_{i t}+\Delta T P_{i t}-D P_{i t}\right) / A T A_{i t}$, where $\Delta C A_{i t}$ is one-year change in current assets, $\triangle C L_{i t}$ is one-year change in current liabilities, $\triangle C_{C a s h}{ }_{i t}$ is one-year change in cash, $\triangle S T D E B T_{i t}$ is one-year change in current liabilities, $\triangle T P_{i t}$ is income tax payable, $D P$ is depreciation expense, and $A T A_{i t}$ is average total assets over years $t-1, t$ and $t+1$.

12 The Acc measure is defined as the decile ranking of the ratio of standard deviation of residual from the regression $T C A_{i t}=\alpha_{t}+$ $\beta_{0 t} / A T A_{i t}+\beta_{1 t} O C F_{i t-1}+\beta_{2 t} O C F_{i t}+\beta_{3 t} O C F_{i t+1}+\beta_{4 t} \Delta R E V_{i t}+\beta_{5 t} P P E_{i t}+\varepsilon_{i t}$, where $T C A_{i t}$ is total current accruals for year $t$ as defined above, $O C F_{i t}$ is operating cash flow for year $t, \triangle R E V_{i t}$ is one-year change in revenues, and $P P E_{i t}$ is property, plant, and equipment for year $t$.
} 
Portfolio-Level Two-stage Asset Pricing Test

We further conduct a two-stage cross-sectional regression (2SCSR) analysis on Fama-French 25 size and BM portfolios to examine possible risk-based asset pricing implications of conditional conservatism. In the first stage, we construct a conservatism factor $R C O N$, which represents return on a zero-investment portfolio buying the top 20 percent of firms and selling the bottom 20 percent of firms sorted by CON, and estimate multivariate betas from time-series regressions of excess returns for a portfolio of firms according to size and $\mathrm{BM}, R_{q t^{-}}$ $R_{F t}$, on contemporaneous portfolio returns to the Fama-French and momentum factors, along with $R C O N$. The first-stage models are:

$$
\begin{aligned}
& R_{q t}-R_{F t}=b_{0}+b_{q, R M_{-} R F}\left(R_{M t}-R_{F t}\right)+b_{q, S M B} S M B_{t}+b_{q, H M L} H M L_{t}+b_{q, R C O N} R C O N_{t}+\varepsilon_{q t} \\
& R_{q t}-R_{F t}=b_{0}+b_{q, R M_{-} R F}\left(R_{M t}-R_{F t}\right)+b_{q, S M B} S M B_{t}+b_{q, H M L} H M L_{t} \\
& \quad+b_{q, A C C} U M D_{t}+b_{q, R C O N} R C O N_{t}+\varepsilon_{q t}
\end{aligned}
$$

with definitions of variables as:

$R_{q t}=$ the average excess return on size-BM portfolio $q$ in month $t$,

$R_{F t}=$ the U.S. one-month T-bill rate in month $t$,

$\operatorname{RCON}_{q t}=$ return on $C O N$ factor as explained above,

$R_{M t}-R_{F t}=$ return on market portfolio (CRSP value-weighted) minus the risk-free rate proxied by the U.S. one-month T-bill rate,

$S M B_{t}=$ return on a factor-mimicking hedge portfolio for size as in Fama and French (1993),

$H M L_{t}=$ return on a factor-mimicking hedge portfolio for BM as in Fama and French (1993),

$U M D_{t}=$ return on a factor-mimicking hedge portfolio for momentum as in Jegadeesh and

Titman (1993). 
The second stage estimates cross-sectional regressions of mean excess factor returns on factor loadings estimated in the first-stage time-series regressions, as follows:

$R_{q t}-R_{F t}=a_{0}+a_{1} b_{q, R M_{-} R F}+a_{2} b_{q, S M B}+a_{3} b_{q, H M L}+a_{4} b_{q, R C O N}+\eta_{q t}$

$R_{q t}-R_{F t}=a_{0}+a_{1} b_{q, R M \_R F}+a_{2} b_{q, S M B}+a_{3} b_{q, H M L}+a_{4} b_{q, U M D}+a_{4} b_{q, R C O N}+\eta_{q t}$

where $b_{q, R M_{-} R F}, b_{q, S M B}, b_{q, H M L}, b_{q, U M D}$, and $b_{q, R C O N}$ are factor loadings estimated in the first stage. If the estimated coefficients for $b_{q, R C O N}$ are significantly positive (negative), then $R C O N$ is deemed to reflect a priced factor with a positive (negative) risk premium.

Methodology for Testing Effects of Information Asymmetry, Fundamental Risk, and

\section{Behavior-based Mispricing}

Using our measures for information asymmetry and fundamental risk, we directly examine their associations with conditional conservatism via a portfolio approach and their roles in explaining the CON-equity cost relation by controlling for them in multivariate regressions. Specifically, we first construct five CON-based portfolios, and check the levels of information asymmetry (IRisk) and earnings downside risk (ERisk) in each portfolio. If high-CON portfolios on average have significantly higher IRisk and/or ERisk, this suggests that conditional conservatism can generally elevate perceptions of information asymmetry and/or earnings downside risk. We then use the following Fama-MacBeth models to investigate the explanatory power of these two influences:

$$
\begin{aligned}
R_{i t+1}-R_{\text {Ft+l }}= & \alpha+\beta_{1} \text { CON }_{i t}+\beta_{2} \text { Beta }_{i t}+\beta_{3} \text { Size }_{i t}+\beta_{4} B M_{i t}+\beta_{5} \text { IRisk }_{i t} \\
& +\sum \text { Industry_Dummies }+\mu_{i t} \\
R_{i t+1}-R_{F t+1}=\alpha & +\beta_{1} \text { CON }_{i t}+\beta_{2} \text { Beta }_{i t}+\beta_{3} \text { Size }_{i t}+\beta_{4} B M_{i t}+\beta_{5} \text { ERisk }_{i t} \\
& +\sum \text { Industry_Dummies }+\mu_{i t} \\
R_{i t+1}-R_{\text {Ft+l }}=\alpha & +\beta_{1} \text { CON }_{i t}+\beta_{2} \text { Beta }_{i t}+\beta_{3} \text { Size }_{i t}+\beta_{4} \text { BM M }_{i t}+\beta_{5} \text { IRisk }_{i t}+\beta_{6} \text { ERisk }_{i t}
\end{aligned}
$$


$+\sum$ Industry_Dummies $+\mu_{i t}$

where $R_{i t+1}, R_{F t+1}, \quad$ Beta $_{i t}, \quad$ Size $_{i t}$, and $C O N_{i t}$ are defined as in models (5)-(10), and Industry_Dummies are Fama and French (1997) industry classifications. If CON affects the cost of equity capital via information asymmetry and/or earnings downside risk, then adding IRisk and ERisk should weaken their relation as reflected in the magnitude and significance levels of the $C O N$ coefficient.

To test the existence of behavior-based mispricing, we adopt a double-sorted portfolio approach that first controls for commonly perceived risk factors like size, BM, and total accruals, and then checks whether high-CON portfolios exhibit high equity costs. We also conduct standard hedging portfolio analysis for $\mathrm{CON}$ in each fiscal year. If a high cost of equity is associated with more conservatism firms after controlling for size and BM, and such a relation does not cluster in any particular year, then mispricing may exist (Bernard et al. 1997). Additional evidence regarding asymmetric loss-aversion is obtained by examining the difference in cost of equity between relatively high-CON portfolios and relatively low-CON portfolios. For example, if the equity cost spread between the top two CON portfolios is larger than that between the bottom two portfolios, then investors' over-reactions to bad earnings news lend support to a mispricing effect.

\section{Data and Main Results on the Relation between Conditional Conservatism and Cost of Equity}

Our sample consists of all common stocks traded on the NYSE, NASDAQ, and AMEX during the period from January 1986 to December 2008. Daily and monthly returns and the U.S. one-month T-bill rates are obtained from CRSP, with corresponding accounting data retrieved from COMPUSTAT. CON estimates are winsorized to the $1 \%$ and $99 \%$ percentiles of Fama and French (1997) industry distributions for each fiscal year to abate potential biases from outliers. 
Insert Table 1 about here

Table 1 reports descriptive statistics for variables used in the main tests. Panel A shows that the mean (median) of $C O N$ and its two components, CON_Acm and CON_Skew, are -0.5035 (-0.5129), 0.0085 (0.0116), and -1.0155 (-1.0303), respectively. ${ }^{13}$ Panel B indicates that the Pearson and Spearman correlations of $C O N$ with CON_Skew and CON_Acm are significantly positive, within the range of 0.1300 to 0.9913 , thus lending construction validity to $C O N$ as a representative conditional conservatism measure. Nonetheless, the Pearson (Spearman) correlation between CON_Skew and CON_Acm is only 0.0018 (0.0623), with the former statistically insignificant, which is not necessarily inappropriate since each gauges conditional conservatism in different dimensions: CON_Skew measures conservatism arising from earnings distribution, while CON_Acm indicates conservatism arising from non-operating assets. In addition, all Pearson and Spearman correlations of conditional conservatism measures with total accruals (TCA) are significantly negative, whereas those with accrual quality (Acc) are significantly positive. This suggests that accounting-based CON measures convey information about total accrual and accrual quality, but this information is not exactly the same as (and therefore cannot be subsumed by) that contained in firms' total accruals and accrual quality.

\section{Hedging Portfolio Analysis}

Table 2 reports hedging portfolio analysis results for average excess returns adjusted for cash flow news and abnormal returns represented by alphas, as well as other relevant measures. We construct five CON-sorted portfolios rebalanced each month, with portfolio 1 representing firms with the smallest (largest) CON. Average cash flow news adjusted excess

\footnotetext{
13 The mean (median) of total accrual TCA is 0.0099 (0.0080), which is higher than the documented negative values in Sloan (1996), due to different sampling periods. The sampling period in this study is 1986 to 2008 , whereas the sampling period in Sloan (1996) is 1962 to 1991 . As we extend the sampling period back to 1962, the mean and median of total accrual become negative, in line with Sloan's (1996) evidence.
} 
returns (Ret) and three abnormal return measures (CAPM alpha, 3-factor alpha, and 4-factor alpha) all increase monotonically with the magnitude of $C O N$, with the average mean differences between the top and bottom portfolios as $0.0053,0.0044,0.0048$, and 0.0056 , respectively, all statistically significant. A similar pattern is observed for Momentum. In contrast, total accruals (TCA) decline monotonically with CON, with an average of 0.0181 for portfolio 1 and 0.0005 for portfolio 5. The mean difference of -0.0176 is statistically significant at the $1 \%$ confidence level, suggesting that $C O N$ is negatively correlated with $T C A$, consistent with evidence in Table 1 . The pattern for accrual quality Acc, although non-monotonic, generally exhibits a positive relation with $C O N$ : the mean difference between portfolios 1 and 5 is 0.0338 , statistically significant at the $1 \%$ confidence level. Overall, Table 2 provides evidence that higher $C O N$ is associated with higher expected returns (alphas or cash flow news adjusted excess return), implying that higher conditional conservatism increases cost of equity. Moreover, $C O N$ is shown to be significantly correlated with return momentum, total accrual, and accrual quality, indicating a need to control for these variables in the multivariate cross-sectional regressions.

Insert Table 2 about here

\section{Firm-Level Fama-MacBeth Cross-sectional Regression Analysis}

Table 3 presents results for Fama-MacBeth cross-sectional regressions of monthly cash flow news adjusted excess returns on $C O N$ and other firm risk characteristics including Beta, Size, BM, Momentum, TCA, and Acc. Following Kim and Qi (2010), we also include Low-priced, an indicator for low-priced shares along with Acc. Panels A and B present results without and with controls for Fama and French (1997) industries, respectively.

Consistent with portfolio analysis results, cross-sectional loadings on CON are consistently positive and significant, with univariate coefficients ( $t$-statistics) of 0.0138 (3.54) and 0.0098 
(3.32), without and with controlling for industry effects, respectively. ${ }^{14}$ After Beta, Size, and BM are added as further controls, $C O N$ coefficients remain significantly positive, with corresponding coefficients ( $t$-statistics) of 0.0091 (3.42) and 0.0063 (2.77) in Panels A and B, respectively. Moreover, CON's effect on the cost of equity is not subsumed by either Momentum, TCA, or Acc when they enter into the regressions individually or collectively, suggesting that $C O N$ provides information beyond that from momentum, total accruals, and accrual quality. Therefore, results in Table 3 reconfirm that conditional conservatism is positively related to cost of equity capital, which cannot be captured by standard risk factors and is not contributable to total accruals and/or accrual quality effects. The relation is also robust to industrial characteristics.

Insert Table 3 about here

\section{Portfolio-Level Two-Stage Cross-Sectional Regressions (2SCSR) Analysis}

To further confirm conditional conservatism's impact on cost of equity, we conduct two-stage cross-sectional regression analysis at the portfolio level, which is less affected by firm-specific characters that may contaminate the underlying relation considered. Table 4 reports estimation results for models (11) to (14). Panel A presents the first-stage time-series regressions of monthly portfolio excess stock returns adjusted for cash flow news on the $C O N$ factor $(R C O N)$ and the three Fama and French (1993) factors and a momentum factor (UMD). Factor loadings on $R C O N$ are significantly positive, with a magnitude ( $t$-statistic) 0.4725 (4.16) when the three Fama-French factors are controlled, and 0.3814 (3.87) when the momentum factor $U M D$ is added as a further control, respectively.

\section{Insert Table 4 about here}

\footnotetext{
${ }^{14}$ Rigorously speaking, Model 1 in Panel B is not an univariate regression because it also includes industry dummy variables. We call it univariate here for simplicity.
} 
Panel B reports results for the second-stage cross-sectional regressions of excess portfolio returns on factor loadings estimated from the first stage. The coefficients for factor loadings on $R C O N\left(\beta_{R C O N}\right)$ are significantly positive with magnitudes (t-statistics) of 0.0051 (3.42) and 0.0055 (3.49) when loadings on Fama and French (1993) three factors and Carhart (1997) four factors are controlled, respectively. The last column indicates that when $\beta_{R C O N}$ is included, average adjusted $R^{2}$ jumps from 0.4170 to 0.7566 for the three-factor model, and from 0.4086 to 0.7530 for the four-factor model. This evidence from the 2SCSR analysis provides further support for $C O N$ as an enhancing force for cost of equity, and the mechanisms that contribute to this positive relation will be explored in next section.

\section{Informational, Fundamental, and Behavioral Effects on the Relation between Conditional Conservatism and Cost of Equity}

\section{Information Asymmetry and Fundamental Risk Effects}

Table 5 reports results from portfolio analyses and Fama-MacBeth cross-sectional regressions for testing propositions regarding the information asymmetry and fundamental risk effects. Panel A presents the mean values of information asymmetry measure IRisk and fundamental (earnings) downside risk measure ERisk in different $\mathrm{CON}$-sorted portfolios, where portfolio 1 (5) contains firms with smallest (largest) CON, respectively. IRisk increases non-monotonically with $C O N$, revealing an asymmetric "V" pattern. It falls from 0.0303 for portfolio 1 to 0.0284 for portfolio 2 , suggesting that conditional conservatism serves to reduce information asymmetry at lower levels, then it increases monotonically from 0.0284 for portfolio 2 to 0.0350 for portfolio 5, implying that $C O N$ increases information asymmetry at higher levels. The mean difference of IRisk between portfolios 5 and 1 is 0.0047 , statistically significant at the $1 \%$ confidence level. Therefore, conditional conservatism is nonlinearly associated with information asymmetry, but on average a positive relation dominates, suggesting that high 
conditional conservatism may be associated with high cost of equity capital since it enhances information asymmetry as suggested by Lambert et al. (2012) and Gow et al. (2011). Similarly, the earnings downside risk measure ERisk increases monotonically with $C O N$, and the mean difference between the top and bottom portfolios is 0.0567 , statistically significant at the $1 \%$ confidence level. Since earnings downside risk has been shown to induce a higher cost of equity (Luo et al. 2011)), this finding suggests that the positive relation of conditional conservatism with downside risk in earnings may also contribute to its positive association with the cost of equity capital.

Insert Table 5 about here

Panel B of Table 5 presents evidence from Fama-MacBeth cross-sectional regressions estimated using models (15) to (17) regarding the explanatory power of information and earnings downside risks on the positive relation between $\mathrm{CON}$ and cost of equity. The coefficients for CON become much smaller than in Panel B of Table 3 where IRisk and ERisk are not controlled. In particular, the coefficient ( $t$-statistic) for CON drops to 0.0053 (2.13) and 0.0049 (2.22), respectively, after adding IRisk and ERisk as further controls in models in Table 5 Panel B, compared with a figure of 0.0063 (2.77) in the model in Table 3 Panel B that only controls for the three Fama-French factors. Importantly, the coefficient ( $t$-statistic) for CON drops to 0.0041 (1.68) when both IRisk and ERisk are controlled. Combined, the findings indicate that either information asymmetry or earnings downside risk partially explains CON effects individually, and they further subsume a larger portion of CON loading when both are included in the model. This evidence lends support to the argument that the positive CON-equity cost relation reflects the effects of information asymmetry and fundamental downside risk.

\section{Behavioral Effect}


If markets are not perfectly efficient, conditional conservatism also holds the potential to increase the cost of equity via mispricing caused by investors' irrational behaviors such as loss-aversion. We test this conjecture following the spirit of Daniel et al. (2001) and Bernard et al. (1997). Daniel et al. (2001) argue that risk factors identified using asset pricing tests may still capture mispricing since size or book-to-market ratio measures include the market value of equity. Bernard et al. (1997) show that a mispricing explanation may exist if returns to a hedging portfolio are consistently positive but do not cluster in any specific period or in firms with small sizes and/or low book-to-market ratios. Guided by these reasoning, we first conduct CON hedging portfolio tests double sorted on $C O N$ and Size or BM. For each month, we assign firm-month observations into two Size portfolios (small-bottom 50\%, large-top 50\%) and three $B M$ portfolios (Low-bottom 30\%, Medium-middle 40\%, High-top 30\%). Then within each portfolio, we further sort stocks into five groups by most recent (with at least a four-month lag) CONs, with group 1 (5) containing firms with small (large) CON.

Table 6 reports test results for the mispricing effect. Panel A shows that Size- and $C O N$-sorted hedging portfolio excess returns (after adjusting for cash flow news) are higher in small firms but do not disappear in large firms, with mean return spreads ( $t$-statistics) of 0.0073 (3.90) and 0.0018 (1.75) between the lowest and highest CON portfolios for small and large size groups, respectively. Similarly, Panel B indicates that $B M$ - and $C O N$-sorted hedging portfolio returns are all significant for high-, medium-, and low-BM firms, with mean return differences ( $t$-statistics) between portfolios 5 and 1 of 0.0078 (5.27), 0.0040 (2.65), and 0.0035 (1.85), respectively. These results suggest that hedging portfolio returns do not concentrate in small or low-BM firms and that behavior-induced mispricing helps explain the documented CON-equity cost relation. 
Insert Table 6 about here

Extending the above method, we further address the concern whether the behavioral effect is a disguise of the accrual anomaly which is also subject to mispricing explanations (Sloan 1996; Xie 2001; Richardson et al. 2005) by constructing portfolios double-sorted on TCA and CON. We first assign firms into three TCA portfolios (Low-bottom 30\%, Medium-middle 40\%, High-top 30\%), and then sort stocks into five CON groups within each portfolio. Results in Panel $\mathrm{C}$ indicate that $C O N$-sorted hedging portfolio returns are all significant for high-, medium-, and low-TCA firms, with mean return differences ( $t$-statistics) between $C O N$ groups 5 and 1 of 0.0031 (1.76), 0.0048 (3.79), and 0.0061 (3.40), respectively. Therefore, despite that the cost of equity spread is relatively smaller among firms with large total accruals, possible mispricing caused by conditional conservatism is not subsumed by and is not a camouflage for accrual anomaly.

We then specifically check whether the CON hedging portfolio returns are clustered in any certain period and report portfolio analysis results for each sample year in Table 7, which shows that for the period prior to 2002 when the SOX was enacted, most years (15 out of total 17 years) exhibit positive average return differences between high- and low-CON portfolios, especially when statistically significant. For the period after 2003, the mean return differences become insignificantly negative, possibly due to mitigated mispricing caused by enhanced financial reporting transparency (and reduced information asymmetry) and market efficiency after SOX, a phenomenon to be explained in more details in Section V. Generally, as suggested by Bernard et al. (1997), the findings provide additional evidence that the positive association between conditional conservatism and cost of equity in the pre-SOX period is partially explained by mispricing effect. 
Insert Table 7 about here

Next we explore the potential causes for the mispricing effect on the association between conditional conservatism and cost of equity. A second look at Table 2 reveals that loss-aversion may be a partial explanation. If there is no overreaction to bad new driven by loss-aversion, then the return spread between CON portfolios 2 and 1 should be no smaller than that between portfolios 5 and 4. Nonetheless, for either cash flow news adjusted excess return Ret or abnormal returns (alphas), the 2-1 return spreads are consistently smaller than the 5-4 return spreads. For example, the differences in Ret between portfolios 2 and 1 and between portfolios 5 and 4 are 0.0014 and 0.0019, respectively, and the corresponding differences in 4-factor alpha are 0.0011 and 0.0023, respectively. Similar observations can be obtained for CAPM and 3-factor alphas too. These findings suggest that over-reaction to bad news via loss-aversion is at least partially responsible for the behavior-related mispricing in explaining the positive relation between conditional conservatism and cost of equity capital.

\section{V.SOX and the Conditional Conservatism - Cost of Equity Relation}

Thus far we have found supporting evidence on the informational, behavioral, and fundamental effects of conditional conservatism on its association with the cost of equity. If these influences play a role, then the passage of SOX provides an ideal natural experiment wherein their effects should be reduced (Chang et al. 2009; Skaife et al. 2009; Amir et al. 2010). ${ }^{15}$ SOX legislation enacted by the U.S. Congress in 2003 in response to allegations of accounting irregularities in Enron and other firms was intended in part to mitigate information asymmetry between firms and investors and enhance market efficiency. Whereas several prior studies

\footnotetext{
${ }^{15}$ Chang et al. (2009) report that SOX reduces cost of equity capital in general by improving financial reporting quality. Skaife et al. (2009) provide evidence that SOX reduces cost of equity via mandatory disclosures of internal control weaknesses. Amir et al. (2010) likewise argue that SOX enhances negative relation between auditor independence and cost of debt capital proxied by bond ratings and yields.
} 
document increased conditional conservatism in the post-SOX period (e.g., Lobo and Zhou 2006; Biddle et al. 2011a), our design lends itself to further detecting potential reductions in equity risk arising from reduced information asymmetry in the post-SOX period, thus complementing prior findings. The decrease in information asymmetry further boosts market efficiency and shrinks potential mispricing. SOX also constrained firms' investment and risk-taking (Kang et al. 2010; Bargeron et al. 2010) and thus their need for new information from the market, implying a diminished feedback effect. A reduction in fundamental business risk in post-SOX era implies a reduced equity premium on earnings downside risk and a lesser role for fundamental risk in affecting the CON-equity cost relation. Based on these arguments, we expect a diminished association between conditional conservatism and equity cost after SOX is enacted. This serves to provide additional support for the informational, behavioral, and fundamental risk influences of conditional conservatism on increasing the cost of equity in the pre-SOX period.

Figure 1 graphically presents per-year average cash flow news adjusted excess returns to CON-sorted portfolios. A striking pattern is observed whereby hedging portfolio returns are consistently positive for most years during the pre-SOX period of 1986-2002. The hedging returns become negative from 2004 through 2008, the post-SOX period, with generally smaller magnitudes and variances compared with the pre-SOX period. The spike in 2003 is consistent with enhanced revelations of bad news associated with the implementation of SOX.

Insert Figure 1 about here

To further examine the influence of SOX, we conduct firm-level Fama-MacBeth cross-sectional regressions of cash flow news adjusted excess returns on $\mathrm{CON}$ and other control variables separately for the pre- and post-SOX periods and report the results in Panels A and B in Table 8, respectively. To avoid possible noise from market reactions to the regulation, we omit 
years when SOX was passed (2002) and implemented (2003). Panel A reveals that the positive CON loadings are driven primarily by observations from the pre-SOX period. In particular, CON is positively and significantly associated with returns in all regressions before the implementation of SOX. Panel B indicates that CON coefficients are generally negative and/or insignificant in the post-SOX period, consistent with Figure 1. In summary, results in pre- and post-SOX periods collectively corroborate the propositions about the information asymmetry, fundamental risk, and behavioral channels through which conditional conservatism enhances the cost of equity capital.

\section{Insert Table 8 about here}

\section{Robustness Checks}

To test the robustness of the main test results, we separately use CON_Skew, CON_Acm, and the ranking of $C O N$ as alternative measures for conditional conservatism, with results qualitatively unchanged. We also adopt two other CON proxies: Skew and CONA. Following Callen et al. (2010), Skew is defined as the difference between the skewness of OCF and earnings estimated over a rolling window of 20 quarters, and CONA is measured as the average of CON_Acm and Skew. Using these proxies also leads to qualitatively similar results. Moreover, extending Botosan et al. (2011), we use analyst forecast error as an alternative proxy for cash flow news, which is computed as the difference between reported annual earnings per share less its analysts' forecast, deflated by month-end stock price. The empirical results are similar to previously reported.

For information asymmetry measures, we alternatively use the annual average of daily high and low spread HLspread following Corwin and Schultz (2011), as well as Itrade following Llorente et al. (2002) and Ferreira and Laux (2007). For earnings downside risk, we utilize Jones 
(1991) model to predict total accruals in calculating ERisk. We further adopt the root lower partial moment of return on asset AERisk as a substitute measure. When these alternative measures for information asymmetry and earnings downside risk are used, results are consistent with those reported in the main tests.

In the asset pricing tests, following McInnis (2010), we drop all return-months in which a firm announces future quarterly earnings to reduce the possibility that improper adjustments for cash flow news may bias the results. We also add liquidity beta as a control for liquidity effects not sufficiently captured by the Low-Priced dummy. Both schemes deliver findings that are qualitatively similar to previously reported. Finally, the address the concern that the results for post-SOX period are driven by the price plump and illiquidity during the 2007-2008 financial crisis, we drop years of 2007 and 2008 from our post-SOX period and replicate Panel B of Table 8, and achieve qualitatively unchanged results.

\section{Conclusions}

Conditional conservatism helps lower cost of equity capital by improving disclosure quality. At the same time, it also affects information asymmetry, influences firms' fundamental operation, and causes possible behavior-driven mispricing, especially in imperfect markets, which holds the potential to increase the cost of equity capital. How conditional conservatism is related to equity cost is determined by the combined effect from these channels. Using accounting-based conditional conservatism measure and cash flow news adjusted expected equity cost proxy, we find a significantly positive relation between conditional conservatism and cost of equity capital that operates via information asymmetry, behavioral mispricing, and earnings downside risk. We provide confirming evidence that the positive association between conditional conservatism and equity capital cost largely disappears in the post-SOX period, 
consistent with mitigated information asymmetry and diminished behavioral influences and fundamental business risk engendered by SOX.

This study contributes to accounting conservatism literature by providing original evidence that conditional conservatism increases the cost of equity capital, and by relating it to informational, behavioral, and fundamental risk dimensions, thus supplementing prior literature about the equity cost decreasing effect of conditional conservatism via improved information quality only. Our findings hold implications for ongoing deliberations regarding the costs and benefits of conservatism as a basic tenet of financial accounting. It also augments the SOX literature by documenting a diminution of the influences of conditional conservatism on cost of capital, suggesting that SOX regulations reduce the cost of equity capital via informational effect, fundamental risk, and behavioral dimensions relevant to conditional conservatism, and connoting the importance of considering regulation-induced structural changes in asset pricing tests.

In this study, we aim at providing a clearer inference about conditional conservatism's impact on cost of equity and propose three mediating channels of informational asymmetry, operational risk, and behavioral mispricing, but with no intention to be exhaustive. In this sense, our findings do not mean to depict all the facets of conditional conservatism, whose relation with cost of equity is by nature complicated. Therefore, the positive relation between conditional conservatism and equity cost documented in this study should be treated as a supplement, rather than as a substitute, for existing evidence on conservatism-capital cost relation that warrants further enquiry. 


\section{REFERENCES}

Akins, B. K., J. Ng, and R. S. Verdi. 2011. Investor competition over information and the pricing of information asymmetry. The Accounting Review, forthcoming.

Armstrong, C., J. Core, D. Taylor, and V. Verrecchia. 2011. When does information asymmetry affect the cost of capital? Journal of Accounting Research 49 (1): 1-40.

Accounting Principles Board. 1970. Statement No. 4: Basic Concepts and Accounting Principles Underlying Financial Statements of Business Enterprises. Stamford, CT: FASB.

Amir, E., Y. Guan, and G. Livne. 2010. Auditor independence and the cost of capital before and after Sarbanes-Oxley: the case of newly issued public debt. European Accounting Review 19(4): 633-664.

Bargeron, L., K. M. Lehn, and C. J. Zutter. 2010. Sarbanes-Oxley and corporate risk-taking. Journal of Accounting and Economics 49(1): 34-52.

Basu, S., 1997. The conservatism principle and the asymmetric timeliness of earnings. Journal of Accounting and Economics 24(1): 3-37.

Benartzi, S., and R. Thaler. 1985. Myopic loss aversion and the equity premium puzzle. Quarterly Journal of Economics, 110(1): 73-92.

Bernard, V., J. Thomas, and J. Wahlen. 1997. Accounting-based stock price anomalies: Separating market inefficiencies from mispricing. Contemporary Accounting Research 14(2): 89-136.

Biddle, G. C., M. Ma, and F. Song. 2011a. Accounting conservatism and bankruptcy risk. Working paper. University of Hong Kong.

Biddle, G. C., M. Ma, and F. Song. 2011b. The risk management role of accounting conservatism for operating cash flows. Working paper. University of Hong Kong.

Biddle, G. C., M. Ma, and Y. Wang. 2011. Timely loan loss recognition and systemic risk in the banking industry. Working paper. University of Hong Kong.

Botosan, C. 2006. Disclosure and the cost of capital: What do we know? Accounting and Business Research 36: 31-40.

Botosan, C. A., M. A. Plumlee, and H. Wen. 2011. The relation between expected returns, realized returns, and firm risk characteristics. Contemporary Accounting Research, forthcoming. 
Callen, J. L., D. Segal, and O-K. Hope. 2010. The pricing of conservative accounting and the measurement of conservatism at the firm-year level. Review of Accounting Studies 15(1): 145-178.

Carhart, M. 1997. On the persistence of mutual fund performance. The Journal of Finance 52(1): 57-82.

Chang, H., G. D. Fernando, and L. Liao. 2009. Sarbanes-Oxley act, perceived earnings quality and cost of capital. Review of Accounting and Finance 8(3): 216-231.

Chen, Q., T. Hemmer, and Y. Zhang. 2007. On the relation between conservatism in accounting standards and incentives for earnings management. Journal of Accounting Research 45(3): 541-565.

Corwin, S. A., and P. Schultz. 2011. A simple way to estimate bid-ask spreads from daily high and low prices. Journal of Finance, forthcoming.

Daniel, K. D., D. Hirshleifer, and A. Subrahmanyam. 2001. Overconfidence, arbitrage, and equilibrium asset pricing. Journal of Finance 56(3): 921-965.

Diamond, D., and R. E. Verrecchia. 1991. Disclosure, liquidity, and the cost of capital. Journal of Finance 46(4): 1325-1359.

Easley, D., and M. O'Hara. 2004. Information and the cost of capital. The Journal of Finance 59(4): 1553-1583.

Epstein, L. G., and M. Schneider. 2008. Ambiguity, information quality and asset pricing. Journal of Finance 63(1): 197-228.

Fama, E. F. and K. R. French. 1992. The Cross-section of expected stock returns. Journal of Finance 47(2): 427-465.

Fama, E. F. and K. R. French. 1993. Common risk factors in the returns on stocks and bonds. Journal of Financial Economics 33(1): 3-56.

Fama, E. F. and K. R. French. 1997. Industry cost of equity. Journal of Financial Economics 43(2): 153-193.

Fama, E. F. and J. MacBeth. 1973. Risk, return and equilibrium: Empirical tests. Journal of Political Economy 81(3): 607-636.

Fan, Q., X. Zhang. 2011. Accounting conservatism, aggregation, and information quality. Contemporary Accounting Research. forthcoming. 
Ferreira, M. A., and P. Laux. 2007. Corporate governance, idiosyncratic risk, and information flow. Journal of Finance 62 (2): 951-989.

Financial Accounting Standards Board. 1980. Statement of Financial Accounting Concepts No. 2: Qualitative Characteristics of Accounting Information. Stamford, CT: FASB.

Financial Accounting Standards Board. 2010. Statement of Financial Accounting Concepts No. 8: Conceptual Framework for Financial Reporting. Stamford, CT: FASB.

Francis, J., R. LaFond, P. Olsson, and K. Schipper. 2004. Cost of equity and earnings attributes. The Accounting Review 79(4): 967-1010.

Gao, P. 2010. Disclosure quality, cost of capital, and investor welfare. The Accounting Review 85(1): 1-29.

Gao, P., and P. J. Liang. 2011. Informational feedback effect, adverse selection, and the optimal disclosure policy. Working paper. University of Chicago.

Givoly, D. and C. Hayn. 2000. The changing time-series properties of earnings, cash flows and accruals: Has financial reporting become more conservative? Journal of Accounting and Economics 29(3): 287-320.

Gow, I. D., D. J. Taylor, and R. E. Verrecchia. 2011. Earnings precision, information asymmetry, and the cost of capital: Evidence of information complementarities. Working paper. Harvard University.

Grossman, S. J., and J. E. Stiglitz. 1980. On the impossibility of informationally efficient markets. The American Economic Review 70(3): 393-408.

Guay, W., and R. E. Verrecchia. 2007. Conservative disclosure. Working paper. University of Pennsylvania.

Haggard, K. S., J. S. Howe, and A. A. Lynch. 2011. Asset write-downs and information asymmetry: Do big baths muddy the waters or clear the air? Working paper. Missouri State University.

Hughes, J. S., J. Liu, and J. Liu. 2007. Information asymmetry, diversification, and cost of capital. The Accounting Review 82(3): 705-730.

International Accounting Standard Board. 2010. Conceptual Framework for Financial Reporting, London: IASB.

Jegadeesh, N. and S. Titman. 1993. Returns to buying winners and selling losers: Implications for stock market efficiency. Journal of Finance 48(1): 65-91. 
Jones, J. 1991. Earnings management during import relief investigations. Journal of Accounting Research 29(2): 193 - 228.

Kahneman, D. and A. Tversky. 1979. Prospect theory: An analysis of decision under risk. Econometrica 47(2): 263-292.

Kang, Q., Q. Liu, and R. Qi. 2010. The Sarbanes-Oxley act and corporate investment: A structural assessment. Journal of Financial Economics 96(2): 291-305.

Khan, M., 2008. Are accruals mispriced? Evidence from tests of an intertemporal capital asset pricing model. Journal of Accounting and Economics 45(1): 55-77.

Kim, B. H., and M. Pevzner. 2010. Conditional accounting conservatism and future negative surprises: An empirical investigation. Journal of Accounting Public Policy 29(4): 311-329.

Kim, D., and Y. Qi. 2010. Accruals quality, stock returns, and macroeconomic conditions. The Accounting Review 85(3): 937-978.

Lambert, and R. E. Verrecchia. 2010. Cost of capital in imperfect competition settings. Working paper. University of Pennsylvania.

Lambert, R., C. Leuz, and R. E. Verrecchia. 2007. Accounting information, disclosure, and the cost of capital. Journal of Accounting Research 45(2): 385-420.

Lambert, R., C. Leuz, and R. E. Verrecchia. 2012. Information asymmetry, information precision, and the cost of capital, Review of Finance 16(1): 1-29.

Lara, JM. G., B. G. Osma, and F. Penalva. 2011. Conditional conservatism and cost of capital. Review of Accounting Studies 16(2):247-271.

Lewellen, J., S. Nagel, and J. Shanken. 2010. A skeptical appraisal of asset pricing tests. Journal of Financial Economics 96(2): 175-194.

Llorente, G., R. Michaely, G. Saar and J. Wang. 2002. Dynamic volume-return relation of individual stocks. The Review of Financial Studies 15(4): 1005-1047.

Lobo, G. J. and Zhou, J., 2006. Did conservatism in financial reporting increase after the Sarbanes-Oxley Act? Initial evidence. Accounting Horizons 20, 57-73.

Luo, Y., M. Ma, and F. Wu. 2011. Earnings downside risk. Working paper. University of Hong Kong.

McInnis, J. 2010. Earnings smoothness, average returns, and implied cost of equity capital. The Accounting Review 85(1): 315-341 
Nan, L., and X. Wen. 2011. Conservatism's effects on capital structure efficiency and information quality. Working paper. University of Illinois at Chicago.

Newey, W., and K. D. West. 1987. A simple, positive semi-definite, heteroskedasticity and autocorrelation consistent covariance matrix. Econometrica 55(3): 703-708.

Ogneva, M. 2010. Accrual quality, realized returns, and expected returns: The importance of controlling for cash flow shocks. Working paper. Stanford University.

Baiman, S., and R. E. Verrecchia. 1996. The relation among capital markets, financial disclosure, production efficiency, and insider trading. Journal of Accounting Research 34(1): 1-22.

Richardson, S. A., R. G. Sloan, M. T. Soliman, and I. Tuna. 2005. Accrual reliability, earnings, persistence and stock prices. Journal of Accounting and Economics 39 (3): 437-485.

Roy, A. D. 1952. Safety first and the holding of assets. Econometrica 20(3): 431-449.

Skaife, H. A., D. W. Collins, W. R. Kinney, and R. LaFond. 2009. The effect of SOX internal control deficiencies on firm risk and cost of equity. Journal of Accounting Research 47(1): 1-43. Sarbanes-Oxley Act of 2002. 2002. Public Law 107-204, 107th U.S. Congress.

Sloan, R. 1996. Do stock prices fully reflect information in accruals and cash flows about future earnings? The Accounting Review 71(3): 289-315.

Suijs, R. 2008. On the value relevance of asymmetric financial reporting policies. Journal of Accounting Research 46(5): 1297-1321.

Veronesi, P. 1999. Stock market overreaction to bad news in good times: A rational expectations equilibrium model. Review of Financial Studies 12(5): 975-1007.

Vuolteenaho, T. 2002. What drives firm-level stock returns? Journal of Finance 57(1): 233-264.

Xie, H. 2001. The mispricing of abnormal accruals. The Accounting Review 76 (3): 357-373.

Zhang, J. 2008. The contracting benefits of accounting conservatism to lenders and borrowers. Journal of Accounting and Economics 45(1): 27-54. 
TABLE 1. Descriptive Statistics for Conditional Conservatism and Firm Characteristic Variables

\begin{tabular}{|c|c|c|c|c|c|c|c|c|c|c|c|}
\hline \multicolumn{12}{|c|}{ Panel A: Summary Statistics } \\
\hline & $C O N$ & CON_Skew & CON_Acm & $T C A$ & $A c c$ & IRisk & ERisk & Size & Beta & $B M$ & Momentum \\
\hline Mean & -0.5035 & -1.0155 & 0.0085 & 0.0099 & 0.0534 & 0.0278 & -0.0063 & 2411.3615 & 1.2276 & 0.6252 & 0.1570 \\
\hline STD & 0.7700 & 0.2000 & 1.5200 & 0.1200 & 0.0500 & 0.0400 & 0.1200 & 12724.7500 & 0.3500 & 0.4400 & 0.5900 \\
\hline Q1 & -0.5780 & -1.1477 & -0.0231 & -0.0316 & 0.0224 & 0.0061 & -0.0544 & 55.9520 & 0.9648 & 0.3256 & -0.1667 \\
\hline Median & -0.5129 & -1.0303 & 0.0116 & 0.0080 & 0.0379 & 0.0170 & -0.0076 & 228.4739 & 1.1726 & 0.5167 & 0.0667 \\
\hline$\underline{\mathrm{Q} 3}$ & -0.4291 & -0.8726 & 0.0425 & 0.0546 & 0.0664 & 0.0362 & 0.0393 & 1007.6076 & 1.4421 & 0.7952 & 0.3403 \\
\hline \multicolumn{12}{|c|}{ Panel B: Correlation Matrix } \\
\hline & $C O N$ & CON_Skew & CON_Acm & $T C A$ & $A c c$ & IRisk & ERisk & Size & Beta & $B M$ & Momentum \\
\hline CON & 1 & 0.1338 & 0.9913 & -0.0068 & 0.2244 & 0.0174 & 0.2947 & -0.0054 & 0.0236 & -0.0005 & 0.0016 \\
\hline CON_Skew & 0.9129 & 1 & 0.0018 & -0.0318 & 0.2552 & 0.0663 & 0.0681 & -0.0426 & 0.1595 & 0.0434 & 0.0255 \\
\hline CON_Acm & 0.4001 & 0.0623 & 1 & -0.0027 & 0.0493 & -0.0158 & 0.2887 & 0.0002 & 0.0027 & -0.0063 & -0.0017 \\
\hline$T C A$ & -0.056 & -0.0375 & -0.0386 & 1 & -0.0451 & -0.0254 & -0.3036 & -0.0018 & 0.0184 & -0.114 & 0.0112 \\
\hline$A c c$ & 0.262 & 0.278 & 0.0547 & -0.0198 & 1 & 0.0419 & 0.0185 & -0.065 & 0.3004 & -0.0714 & 0.0119 \\
\hline IRisk & 0.0546 & 0.0942 & $\mathbf{- 0 . 0 6 9 9}$ & 0.0095 & 0.1154 & 1 & 0.0054 & -0.118 & 0.0588 & $\mathbf{0 . 3 5 3 7}$ & 0.0653 \\
\hline ERisk & 0.1447 & 0.0629 & 0.2484 & -0.327 & -0.0026 & -0.0112 & 1 & 0.0234 & 0.0099 & 0.0022 & 0.0268 \\
\hline Size & -0.1047 & -0.1442 & 0.0564 & 0.0221 & -0.2798 & -0.7671 & 0.0448 & 1 & -0.1202 & -0.1248 & -0.0019 \\
\hline Beta & 0.1474 & 0.1531 & 0.0518 & 0.0198 & 0.3271 & 0.0808 & -0.034 & -0.2068 & 1 & 0.0114 & 0.0331 \\
\hline$B M$ & 0.0093 & 0.0305 & -0.0622 & -0.1314 & -0.088 & 0.362 & -0.009 & -0.4294 & -0.0036 & 1 & 0.0619 \\
\hline Momentum & -0.0051 & -0.0162 & 0.0213 & 0.0019 & -0.0717 & 0.0018 & 0.0412 & 0.1026 & -0.0527 & 0.0472 & 1 \\
\hline
\end{tabular}

This table reports descriptive statistics for conditional conservatism measures and firm characteristic variables for the sample period of January 1986 to December 2008. Panel A shows summary statistics, and Panel B presents Pearson and Spearman correlations among these variables in the upper and lower triangles, respectively. Highlighted numbers are statistically significant at the $10 \%$ level. Variable definitions are available in Sections II. 


\section{TABLE 2. CON-Sorted Portfolio Analysis for Average Monthly Cash Flow News Adjusted}

Excess Return, Alphas, Momentum, Total Accrual, and Accrual Quality

\begin{tabular}{lccccccc}
\hline Portfolio & Ret & CAPM alpha & 3-factor alpha & 4-factor alpha & Momentum & TCA & Acc \\
\hline 1 & 0.0074 & 0.0031 & 0.0015 & 0.003 & 0.1354 & 0.0181 & 0.0431 \\
2 & 0.0088 & 0.0044 & 0.0027 & 0.0041 & 0.1425 & 0.0132 & 0.0402 \\
3 & 0.0096 & 0.0049 & 0.0035 & 0.0053 & 0.1511 & 0.0129 & 0.0455 \\
4 & 0.0108 & 0.0058 & 0.0047 & 0.0062 & 0.175 & 0.0093 & 0.0569 \\
5 & 0.0127 & 0.0074 & 0.0063 & 0.0085 & 0.1772 & 0.0005 & 0.0769 \\
$(5-1)$ & 0.0053 & 0.0044 & 0.0048 & 0.0056 & 0.0418 & -0.0176 & 0.0338 \\
$t$-statistic & $(3.96)^{* * * *}$ & $(3.70)^{* * * *}$ & $(4.63)^{* * *}$ & $(4.87)^{* * * *}$ & $(5.60)^{* * *}$ & $(-23.68)^{* * * *}$ & $(40.75)^{* * * *}$ \\
\hline
\end{tabular}

The table compares cash flow news adjusted excess returns, abnormal returns (alphas), momentum, total accruals, and accrual quality across five portfolios formed on conditional conservatism (CON) for a sample of 62,833 observations of firms listed on the NYSE, NASDAQ, and Amex with available CON measures over the period of January 1986 to December 2008. At the end of each month, firm-month observations are assigned into five portfolios based on the firm's most recent CON known four or more months prior to the current date. Portfolio 1 (5) contains firms with the smallest (largest) CON. Average differences between the top and bottom portfolios are reported in the row (5-1). The $t$-statistics for these differences are computed with a Newey and West (1987) correction. Ret refers to return excluding cash flow news and risk free rate, CAPM alpha, 3-factor alpha and 4-factor alpha refer to abnormal returns from CAPM, Fama-French three-factor model, and Fama-French-Cahart four-factor model, respectively, TCA is total accruals (Sloan 1996) and Acc is accrual quality (Kim and Qi 2010). 
TABLE 3. Fama-MacBeth Regressions of Monthly Cash Flow News Adjusted Excess Return on Conditional Conservatism and Other Firm Characteristics

\begin{tabular}{|c|c|c|c|c|c|c|c|c|c|}
\hline Model & CON & Beta & Size & $B M$ & Momentum & $T C A$ & $A c c$ & Low_Priced & Avg. Adj. R-square \\
\hline \multirow[t]{2}{*}{1} & 0.0138 & & & & & & & & 0.0017 \\
\hline & $(3.54)^{* * *}$ & & & & & & & & \\
\hline \multirow[t]{2}{*}{2} & 0.0091 & 0.0029 & -0.0014 & 0.0022 & & & & & 0.0256 \\
\hline & $(3.42)^{* * *}$ & $(0.92)$ & $(-2.75)^{* * *}$ & $(2.46)^{* *}$ & & & & & \\
\hline \multirow[t]{2}{*}{3} & 0.0088 & 0.0019 & -0.0015 & 0.0022 & 0.0022 & & & & 0.0325 \\
\hline & $(3.41)^{* * *}$ & $(0.68)$ & $(-3.01)^{* * *}$ & $(2.52)^{* *}$ & (1.24) & & & & \\
\hline \multirow[t]{2}{*}{4} & 0.0085 & 0.0031 & -0.0014 & 0.0017 & & -0.0171 & & & 0.0267 \\
\hline & $(3.24)^{* * *}$ & $(1.01)$ & $(-2.78)^{* * *}$ & $(1.97)^{* *}$ & & $(-5.88)^{* * *}$ & & & \\
\hline \multirow[t]{2}{*}{5} & 0.0115 & 0.0023 & -0.0021 & 0.0026 & & & 0.0324 & -0.0158 & 0.0345 \\
\hline & $(5.24)^{* * *}$ & $(0.77)$ & $(-4.85)^{* * *}$ & $(3.45)^{* * * *}$ & & & $(2.45)^{* *}$ & $(-8.46)^{* * *}$ & \\
\hline \multirow[t]{2}{*}{6} & 0.0107 & 0.0018 & -0.0022 & 0.0023 & 0.0000 & -0.0169 & 0.0295 & -0.0158 & 0.0419 \\
\hline & $(4.94)^{* * *}$ & $(0.65)$ & $(-5.11)^{* * *}$ & $(2.97)^{* * *}$ & $(0.03)$ & $(-5.78)^{* * *}$ & $(2.38)^{* * *}$ & $(-9.30)^{* * *}$ & \\
\hline \multicolumn{10}{|c|}{ Panel B: Regressions with Industry Dummies } \\
\hline Model & CON & Beta & Size & $B M$ & Momentum & $T C A$ & $A c c$ & Low_Priced & Avg. Adj. R-square \\
\hline \multirow[t]{2}{*}{1} & 0.0098 & & & & & & & & 0.0367 \\
\hline & $(3.32)^{* * *}$ & & & & & & & & \\
\hline \multirow[t]{2}{*}{2} & 0.0063 & 0.0025 & -0.0013 & 0.0025 & & & & & 0.0535 \\
\hline & $(2.77)^{* * *}$ & $(0.95)$ & $(-2.72)^{* * *}$ & $(3.65)^{* * *}$ & & & & & \\
\hline \multirow[t]{2}{*}{3} & 0.0061 & 0.0018 & -0.0014 & 0.0026 & 0.0008 & & & & 0.0587 \\
\hline & $(2.73)^{* * *}$ & $(0.74)$ & $(-2.97)^{* * *}$ & $(3.77)^{* * *}$ & $(0.48)$ & & & & \\
\hline \multirow[t]{2}{*}{4} & 0.0059 & 0.0027 & -0.0013 & 0.0021 & & -0.0151 & & & 0.0544 \\
\hline & $(2.59)^{* * *}$ & $(1.04)$ & $(-2.75)^{* * *}$ & $(3.07)^{* * *}$ & & $(-5.75)^{* * *}$ & & & \\
\hline \multirow[t]{2}{*}{5} & 0.0106 & 0.0032 & -0.0023 & 0.0025 & & & 0.0103 & -0.0159 & 0.0626 \\
\hline & $(5.01)^{* * *}$ & $(1.26)$ & $(-5.35)^{* * *}$ & $(3.89)^{* * *}$ & & & $(0.96)$ & $(-8.90)^{* * *}$ & \\
\hline \multirow[t]{2}{*}{6} & 0.0099 & 0.0028 & -0.0024 & 0.0023 & -0.0013 & -0.0156 & 0.0087 & -0.0164 & 0.0682 \\
\hline & $(4.71)^{* * * *}$ & $(1.19)$ & $(-5.60)^{* * * *}$ & $(3.54)^{* * *}$ & $(-0.85)$ & $(-5.62)^{* * *}$ & $(0.85)$ & $(-10.00)^{* * *}$ & \\
\hline
\end{tabular}

This table presents estimation results for Fama-MacBeth regressions of monthly cash flow news adjusted excess returns against conditional conservatism $(C O N)$ and other firm characteristics including Beta, Size, BM, Momentum, TCA, Acc, and a low-priced return indicator variable for the period of January 1986 to December 2008. The reported estimates are time-series averages of coefficients from 276 monthly cross-sectional regressions. The $t$-statistics are calculated from Newey and West (1987) standard errors of these monthly averages. Panel A reports results without controlling for Fama and French (1997) industry effect, whereas Panel B reports results after controlling for industry effect by adding dummies for the Fama-French industries. Monthly cash flow news adjusted excess returns are calculated as the raw return less cash flow news and the risk free return proxied by U.S. one-month T-bill rate. Beta is estimated following the procedure in Fama and French (1992). Size is the natural $\log$ of market capitalization. $B M$ is the natural $\log$ of the ratio of book value of equity to market value of equity. We match Beta, Size, and BM measures with return data following Fama and French (1992). Momentum is an 11-month return in the prior-year omitting the most recent month. $C O N$ is the average of firm-year conditional conservatism measure CON_Acm and CON_Skew, TCA is total accrual (Sloan 1996), Acc is the accrual quality measure used in Kim and Qi (2010) and Ogneva (2010). We match annual estimates of CON, TCA, and Acc with monthly stock returns in the next 12 months starting four months after the fiscal year end. The low-priced return indicator is set to 1 if returns are computed using two adjacent prices less than \$5 and 0 otherwise. The main models used in Panels A and B are estimated using models (5) through (10) described in Section II. 
TABLE 4. Portfolio-level Two-stage Cross-Sectional Regressions

\begin{tabular}{lccccccc}
\hline Panel A: & First-stage & Time-series Regressions of Portfolio Returns on Factor Returns & \\
\hline Model & Intercept & $R M-R F$ & $S M B$ & HML & UMD & RCON & Adj. R-square \\
\hline 1 & 0.0053 & 1.0925 & 0.8475 & 0.2868 & & & 0.7626 \\
& $(4.54)^{* * * *}$ & $(42.25)^{* * *}$ & $(11.83)^{* * * *}$ & $(4.05)^{* * *}$ & & & \\
2 & 0.0031 & 1.0292 & 0.7242 & 0.333 & & 0.4725 & 0.7857 \\
& $(3.37)^{* * * *}$ & $(31.14)^{* * *}$ & $(13.71)^{* * *}$ & $(4.92)^{* * *}$ & & $(4.16)^{* * *}$ & \\
3 & 0.0077 & 1.0457 & 0.8665 & 0.2272 & -0.2305 & & 0.7834 \\
& $(6.38)^{* * * *}$ & $(41.16)^{* * *}$ & $(11.96)^{* * * *}$ & $(3.06)^{* * *}$ & $(-11.26)^{* * *}$ & & \\
4 & 0.0056 & 1.0003 & 0.7647 & 0.2718 & -0.2023 & 0.3814 & 0.8024 \\
& $(6.74)^{* * * *}$ & $(30.52)^{* * *}$ & $(14.38)^{* * * *}$ & $(3.83)^{* * *}$ & $(-11.70)^{* * *}$ & $(3.41)^{* * *}$ & \\
\hline
\end{tabular}

Panel B: Second-stage Cross-sectional Regressions of Portfolio Returns on Factor Loadings

\begin{tabular}{lccccccc}
\hline Model & Intercept & $\beta_{R M-R F}$ & $\beta_{S M B}$ & $\beta_{H M L}$ & $\beta_{U M D}$ & $\beta_{R C O N}$ & Adj. R-square \\
\hline 1 & 0.0250 & -0.0184 & 0.0061 & 0.0051 & & & 0.4170 \\
& $(2.60)^{* * * *}$ & $(-2.42)^{* * *}$ & $(2.21)^{* * *}$ & $(1.95)^{* *}$ & & & \\
2 & 0.0282 & -0.018 & -0.0049 & 0.0091 & & 0.0051 & 0.7566 \\
& $(4.52)^{* * *}$ & $(-3.66)^{* * *}$ & $(1.82)$ & $(4.93)^{* * *}$ & & $(3.42)^{* * * *}$ & \\
3 & 0.0263 & -0.0214 & 0.0045 & 0.007 & -0.009 & & 0.4086 \\
& $(2.68)^{* * *}$ & $(-2.53)^{* *}$ & $(1.33)$ & $(1.98)^{* *}$ & $(-0.61)$ & & \\
4 & 0.0275 & -0.0159 & -0.0044 & 0.0079 & 0.0050 & 0.0055 & 0.7530 \\
& $(4.36)^{* * *}$ & $(-2.90)^{* * *}$ & $(-1.59)$ & $(3.45)^{* * *}$ & $(-0.51)$ & $(3.49)^{* * * *}$ & \\
\hline
\end{tabular}

This table shows results of Fama-French 25 portfolio-level two-stage cross-sectional regressions for a sample over the 1986-2008 period. Panel A reports average factor loadings and adjusted $R^{2}$ of the first-stage time-series regressions of monthly portfolio cash flow news adjusted excess returns against the three Fama-French factors, a momentum factor, and a conservatism factor RCON, using models (11) and (12) described in Section II. We construct $R C O N$ as the return on a zero-investment portfolio by buying the top 20 percent of firms and selling the bottom 20 percent of firms in terms of CON. Panel B reports estimated coefficients for the second-stage cross-sectional regressions of excess portfolio returns on portfolio factor loadings estimated from the first stage, according to models (13) and (14) in Section II. 
TABLE 5. CON-Sorted Portfolio Analysis and Fama-MacBeth Regression of Cash Flow News Adjusted Excess Return on Conditional Conservatism, Information Risk, and Earnings Downside Risk

\begin{tabular}{|c|c|c|c|c|c|c|c|}
\hline \multicolumn{2}{|l|}{ CON Portfolio } & \multicolumn{2}{|c|}{ IRisk } & & \multicolumn{3}{|c|}{ ERisk } \\
\hline 1 & & \multicolumn{2}{|c|}{0.0303} & & \multicolumn{3}{|c|}{-0.0313} \\
\hline 2 & & \multicolumn{2}{|c|}{0.0284} & & \multicolumn{3}{|c|}{-0.0109} \\
\hline 3 & & \multicolumn{2}{|c|}{0.031} & & \multicolumn{3}{|c|}{-0.0108} \\
\hline 4 & & \multicolumn{2}{|c|}{0.0341} & & \multicolumn{3}{|c|}{-0.0063} \\
\hline 5 & & \multicolumn{2}{|c|}{0.035} & & \multicolumn{3}{|c|}{0.0254} \\
\hline$(5-1)$ & & \multicolumn{2}{|c|}{0.0047} & & \multicolumn{3}{|c|}{0.0567} \\
\hline$t$-statistic & & \multicolumn{2}{|c|}{$(24.11)^{* * *}$} & & \multicolumn{3}{|c|}{$(38.95)^{* * *}$} \\
\hline \multicolumn{8}{|c|}{ Panel B: Fama-MacBeth Regressions with Industry Dummies } \\
\hline Model & CON & Beta & Size & $B M$ & IRisk & ERisk & Avg. Adj. R-square \\
\hline 1 & $\begin{array}{l}0.0053 \\
(2.13)^{* *}\end{array}$ & $\begin{array}{l}0.0036 \\
(1.29)\end{array}$ & $\begin{array}{c}-0.0004 \\
(-0.65)\end{array}$ & $\begin{array}{l}0.0022 \\
(2.92)^{* * *}\end{array}$ & $\begin{array}{c}0.1522 \\
(4.13)^{* * *}\end{array}$ & & 0.0545 \\
\hline 2 & $\begin{array}{l}0.0049 \\
(2.22)^{* *}\end{array}$ & $\begin{array}{c}0.0021 \\
(0.80)\end{array}$ & $\begin{array}{l}-0.0012 \\
(-2.73)^{* * *}\end{array}$ & $\begin{array}{c}0.0025 \\
(3.63)^{* * *}\end{array}$ & & $\begin{array}{c}0.0152 \\
(5.10)^{* * * *}\end{array}$ & 0.0555 \\
\hline 3 & $\begin{array}{l}0.0041 \\
(1.68)^{*}\end{array}$ & $\begin{array}{c}0.0034 \\
(1.18)\end{array}$ & $\begin{array}{c}-0.0004 \\
(-0.85)\end{array}$ & $\begin{array}{c}0.0024 \\
(3.01)^{* * * *}\end{array}$ & $\begin{array}{c}0.1595 \\
(4.06)^{* * *}\end{array}$ & $\begin{array}{c}0.0145 \\
(4.32)^{* * * *}\end{array}$ & 0.0561 \\
\hline
\end{tabular}

This table presents estimation results for testing the information asymmetry and earnings downside risk effects on the conditional conservatism and equity costs relation. Panel A reports results from portfolio analyses for information asymmetry proxy IRisk and earnings downside risk measure ERisk. At the end of each month, firm-month observations are assigned into one of five portfolios based on a firm's most recent $C O N$ known at least four or more months prior to the current date. Portfolio 1 (5) contains firms with the smallest (largest) CON. Average differences in IRisk and ERisk between the top and bottom portfolios are reported in row (5-1). The $t$-statistics for these differences are computed with a Newey-West (1987) correction. Panel B shows results for Fama-MacBeth regressions of future monthly cash flow news adjusted excess return on CON, IRisk, ERisk, and other firm characteristics (Beta, Size, BM). The reported estimates are time-series averages of the coefficients on $C O N$ from 276 monthly cross-sectional regressions. Reported $t$-statistics are calculated from Newey and West (1987) standard errors of these monthly averages. Panel B presents results estimated using models (15) to (17) as described in Section II. Other variable definitions are the same as for models (5) to (10). 
TABLE 6. CON Portfolio Returns by Size, Book-to-Market, and Total Accruals

\begin{tabular}{|c|c|c|c|c|c|c|c|}
\hline & 1 Low & 2 & 3 & 4 & 5 High & $(5-1)$ & $t$-statistic \\
\hline Small & 0.0092 & 0.0115 & 0.0121 & 0.0143 & 0.0165 & 0.0073 & $(3.90)^{* * *}$ \\
\hline Large & 0.0059 & 0.0063 & 0.0075 & 0.0075 & 0.0076 & 0.0018 & $(1.75)^{*}$ \\
\hline \multicolumn{8}{|c|}{ Panel B: Portfolio Returns Sorted by BM and CON } \\
\hline & 1 Low & 2 & 3 & 4 & 5 High & $(5-1)$ & $t$-statistic \\
\hline High & 0.0095 & 0.0127 & 0.0142 & 0.0135 & 0.0173 & 0.0078 & $(5.27)^{* * *}$ \\
\hline Medium & 0.0082 & 0.0084 & 0.0083 & 0.0101 & 0.0123 & 0.004 & $(2.65)^{* * *}$ \\
\hline Low & 0.0048 & 0.0056 & 0.0068 & 0.0084 & 0.0083 & 0.0035 & $(1.85)^{*}$ \\
\hline \multicolumn{8}{|c|}{ Panel C: Portfolio Returns Sorted by TCA and CON } \\
\hline & 1 Low & 2 & 3 & 4 & 5 High & $(5-1)$ & $t$-statistic \\
\hline High & 0.0061 & 0.0061 & 0.0084 & 0.0071 & 0.0093 & 0.0031 & $(1.76)^{*}$ \\
\hline Medium & 0.007 & 0.008 & 0.0087 & 0.0105 & 0.0119 & 0.0048 & $(3.79)^{* * *}$ \\
\hline Low & 0.0101 & 0.0126 & 0.0126 & 0.0146 & 0.0162 & 0.0061 & $(3.40)^{* * *}$ \\
\hline
\end{tabular}

This table compares average returns excluding cash flow news and risk-free rates for portfolios double sorted on conditional conservatism and Size, BM, or TCA, respectively. For each month during the period of January 1986 through December 2008, firm-month observations are assigned into two size groups (Small, Large), or three BM groups (Low-bottom 30\%, Medium-middle 40\%, High-top 30\%), or three TCA groups (Low-bottom 30\%, Medium-middle 40\%, High-top 30\%), according to market capitalization, the book-to-market ratio, and total accrual defined in Section II. Five portfolios based on a firm's most recent CON (with a minimum four-month lag) are constructed within each Size, BM, or TCA group, and the differences between the top and bottom portfolios are reported in the (5-1) column. The $t$-statistics for these differences are computed with Newey and West (1987) correction. 
TABLE 7. CON Portfolio Analysis for Cash Flow News Adjusted Excess Return by Year

\begin{tabular}{|c|c|c|c|c|c|c|c|}
\hline Year & 1 Low & 2 & 3 & 4 & 5 High & $(5-1)$ & $t$-statistic \\
\hline 1986 & -0.0011 & 0.0086 & 0.008 & 0.0015 & 0.0063 & 0.0074 & $(1.67)^{*}$ \\
\hline 1987 & -0.0024 & 0 & 0.0038 & 0.0004 & 0.0039 & 0.0063 & (1.07) \\
\hline 1988 & 0.0191 & 0.0142 & 0.0186 & 0.0162 & 0.0161 & -0.003 & $(-0.7)$ \\
\hline 1989 & 0.0093 & 0.0076 & 0.0095 & 0.0087 & 0.0149 & 0.0056 & $(1.69)^{*}$ \\
\hline 1990 & -0.0171 & -0.0161 & -0.0143 & -0.0133 & -0.0154 & 0.0017 & $(0.49)$ \\
\hline 1991 & 0.0241 & 0.0294 & 0.0305 & 0.0382 & 0.0377 & 0.0136 & $(2.76)^{* * *}$ \\
\hline 1992 & 0.0127 & 0.015 & 0.0129 & 0.0187 & 0.0203 & 0.0076 & $(1.85)^{*}$ \\
\hline 1993 & 0.0131 & 0.0137 & 0.0154 & 0.0145 & 0.0189 & 0.0058 & (1.34) \\
\hline 1994 & 0.0011 & 0.0032 & 0.001 & 0.0016 & 0.0021 & 0.001 & $(0.46)$ \\
\hline 1995 & 0.0159 & 0.0182 & 0.0155 & 0.0227 & 0.03 & 0.0141 & $(4.41)^{* * *}$ \\
\hline 1996 & 0.0111 & 0.014 & 0.0155 & 0.0192 & 0.0152 & 0.0041 & (1.12) \\
\hline 1997 & 0.0147 & 0.0181 & 0.0187 & 0.0178 & 0.0178 & 0.0031 & $(0.91)$ \\
\hline 1998 & -0.0035 & -0.0005 & 0.0026 & 0.0025 & 0.0036 & 0.0071 & (1.35) \\
\hline 1999 & 0.0163 & 0.0186 & 0.018 & 0.0227 & 0.0345 & 0.0182 & $(2.20)^{* *}$ \\
\hline 2000 & 0.0038 & 0.0037 & 0.0022 & 0.0101 & 0.0052 & 0.0014 & $(0.12)$ \\
\hline 2001 & 0.0209 & 0.0208 & 0.0279 & 0.028 & 0.0398 & 0.0189 & $(2.44)^{* *}$ \\
\hline 2002 & -0.0046 & -0.0047 & -0.0075 & -0.007 & -0.0073 & -0.0027 & $(-0.31)$ \\
\hline 2003 & 0.0335 & 0.0394 & 0.046 & 0.0513 & 0.067 & 0.0335 & $(3.56)^{* * *}$ \\
\hline 2004 & 0.018 & 0.0175 & 0.0172 & 0.0174 & 0.0131 & -0.0049 & $(-0.78)$ \\
\hline 2005 & 0.0099 & 0.0067 & 0.0073 & 0.008 & 0.0051 & -0.0048 & $(-1.28)$ \\
\hline 2006 & 0.013 & 0.0128 & 0.0138 & 0.0103 & 0.0119 & -0.001 & $(-0.20)$ \\
\hline 2007 & 0.0017 & 0.0004 & -0.0046 & 0.002 & -0.0034 & -0.0051 & $(-1.44)$ \\
\hline 2008 & -0.0385 & -0.0381 & -0.0381 & -0.0441 & -0.0454 & -0.0069 & $(-1.48)$ \\
\hline
\end{tabular}

This table presents annual average returns excluding cash flow news and risk-free rates across five portfolios of conditional conservatism (CON) for each year from 1986 to 2008. For each month, firm-month observations are assigned into five portfolios based on a firm's most recent CON (with a minimum four-month lag). Portfolio 1 (5) contains firms with the smallest (largest) $C O N$. Then excess returns for portfolio 1 to 5 stocks are averaged, and the average differences between the top and bottom portfolios are reported in the column (5-1) by year. The $t$-statistics for these differences are computed with Newey and West (1987) correction. 
TABLE 8. SOX and Fama-MacBeth Regressions of Cash Flow News Adjusted Excess Return on Conditional Conservatism and Firm Characteristics with Industry Dummies

\begin{tabular}{|c|c|c|c|c|c|c|c|c|c|c|c|}
\hline Model & $C O N$ & Beta & Size & $B M$ & Momentum & $T C A$ & $A c c$ & Low-Priced & IRisk & ERisk & Ave Adi R-square \\
\hline \multirow{2}{*}{1} & 0.0124 & & & & & & & & & & 00334 \\
\hline & $(3.87)^{* * *}$ & & & & & & & & & & \\
\hline \multirow[t]{2}{*}{2} & 0.0095 & 0.0032 & -0.0011 & 0.0028 & & & & & & & 0.0505 \\
\hline & $(3.62)^{* * *}$ & (1.10) & $(-1.80)^{*}$ & $(3.20)^{* * *}$ & & & & & & & \\
\hline \multirow[t]{2}{*}{3} & 0.0094 & 0.0023 & -0.0013 & 0.0027 & 0.003 & & & & & & 0.0554 \\
\hline & $(3.63)^{* * *}$ & (0.89) & $(-2.02)^{* *}$ & $(3.17)^{* * *}$ & $(1.72)^{*}$ & & & & & & \\
\hline \multirow[t]{2}{*}{4} & 0.0088 & 0.0035 & -0.0012 & 0.0022 & & -0.0198 & & & & & 0.0515 \\
\hline & $(3.36)^{* * *}$ & (1.19) & $(-1.82)^{*}$ & $(2.55)^{* *}$ & & $(-6.02)^{* * *}$ & & & & & \\
\hline \multirow[t]{2}{*}{5} & 0.0124 & 0.0032 & -0.002 & 0.0029 & & & 0.023 & -0.0154 & & & 0.0611 \\
\hline & $(5.06)^{* * *}$ & (1.15) & $(-3.64)^{* * *}$ & $(3.51)^{* * *}$ & & & $(1.56)$ & $(-6.72)^{* * *}$ & & & \\
\hline \multirow[t]{2}{*}{6} & 0.0086 & 0.0046 & -0.0002 & 0.0026 & & & & & 0.0816 & & 0.0499 \\
\hline & $(2.93)^{* * *}$ & $(1.45)$ & $(-0.31)$ & $(2.75)^{* * *}$ & & & & & $(3.55)^{* * *}$ & & \\
\hline \multirow[t]{2}{*}{7} & 0.0082 & 0.0028 & -0.0011 & 0.0028 & & & & & & 0.0207 & 0.0523 \\
\hline & $(3.24)^{* * *}$ & $(0.92)$ & $(-1.80)^{*}$ & $(3.14)^{* * *}$ & & & & & & $(5.84)^{* * * *}$ & \\
\hline \multirow[t]{2}{*}{8} & 0.0105 & 0.0061 & -0.0013 & 0.0017 & 0.0004 & -0.0207 & 0.0115 & -0.0206 & 0.1434 & 0.0163 & 0.0684 \\
\hline & $(3.44)^{* * *}$ & $(2.18)^{* *}$ & $(-1.94)^{*}$ & $(1.69)^{*}$ & $(0.20)$ & $(-4.80)^{* * *}$ & $(0.72)$ & $(-9.43)^{* * *}$ & $(5.47)^{* * *}$ & $(3.57)^{* * * *}$ & \\
\hline \multicolumn{12}{|c|}{ Panel B: } \\
\hline Model & CON & Beta & Size & $B M$ & Momentum & $T C A$ & $A c c$ & Low-Priced & IRisk & ERisk & Ave. Adj. R-square \\
\hline \multirow[t]{2}{*}{1} & -0.0073 & & & & & & & & & & 0.0449 \\
\hline & $(-1.31)$ & & & & & & & & & & \\
\hline \multirow[t]{2}{*}{2} & -0.0062 & -0.0046 & -0.0005 & 0.0011 & & & & & & & 0.0559 \\
\hline & $(-1.60)$ & $(-1.14)$ & $(-0.91)$ & $(0.96)$ & & & & & & & \\
\hline \multirow[t]{2}{*}{3} & -0.0063 & -0.0045 & -0.0007 & 0.0012 & -0.0009 & & & & & & 0.0604 \\
\hline & $(-1.58)$ & $(-1.18)$ & $(-1.11)$ & (1.05) & $(-0.31)$ & & & & & & \\
\hline 4 & -0.0058 & -0.0043 & -0.0006 & 0.0011 & & -0.0012 & & & & & 0.0565 \\
\hline
\end{tabular}




\begin{tabular}{|c|c|c|c|c|c|c|c|c|c|c|c|}
\hline & $(-1.55)$ & $(-1.06)$ & $(-0.95)$ & $(0.99)$ & & $(-0.28)$ & & & & & \\
\hline \multirow[t]{2}{*}{5} & 0.0046 & -0.0025 & -0.0022 & 0.001 & & & -0.0145 & -0.0212 & & & 0.0599 \\
\hline & $(-1.19)$ & $(-0.63)$ & $(-4.35)^{* * *}$ & $(0.86)$ & & & $(-1.51)$ & $(-7.57)^{* * * *}$ & & & \\
\hline \multirow[t]{2}{*}{6} & -0.0068 & -0.0043 & 0.0003 & 0.0007 & & & & & 0.3126 & & 0.0595 \\
\hline & $(-1.71)^{*}$ & $(-1.09)$ & $(-0.57)$ & $(0.62)$ & & & & & $(2.33)^{* *}$ & & \\
\hline \multirow[t]{2}{*}{7} & -0.0057 & -0.0046 & -0.0007 & 0.001 & & & & & & -0.0002 & 0.0572 \\
\hline & $(-1.51)$ & $(-1.14)$ & $(-1.17)$ & $(0.83)$ & & & & & & $(-0.04)$ & \\
\hline \multirow[t]{2}{*}{8} & 0.0027 & -0.0014 & -0.0004 & 0.0007 & -0.0057 & -0.0015 & -0.006 & -0.0258 & 0.6457 & 0.0059 & 0.0714 \\
\hline & $(-0.71)$ & $(-0.38)$ & $(-0.73)$ & $(0.60)$ & $(-2.02)^{* *}$ & $(-0.35)$ & $(-0.61)$ & $(-8.98)^{* * *}$ & $(4.36)^{* * *}$ & $(-0.89)$ & \\
\hline
\end{tabular}

This table presents estimation results for Fama-MacBeth regressions of monthly cash flow news adjusted excess return on conditional conservatism $(C O N)$, total accruals $(T C A)$, accrual quality (Acc) (along with a low-priced return indicator variable Low-Priced), information asymmetry (IRisk), earnings downside risk (ERisk), and firm characteristics including Beta, Size, and BM, plus controls for dummies for Fama and French (1997) industries. Panel A reports average regression coefficients for the period of January 1986 to December 2001, a period before SOX; Panel B reports average coefficients for the period of January 2004 to December 2008, a period after SOX. 


\section{FIGURE 1. Mean Differences in Cash Flow News Adjusted Excess Return for CON-Sorted Hedging Portfolios by Year}

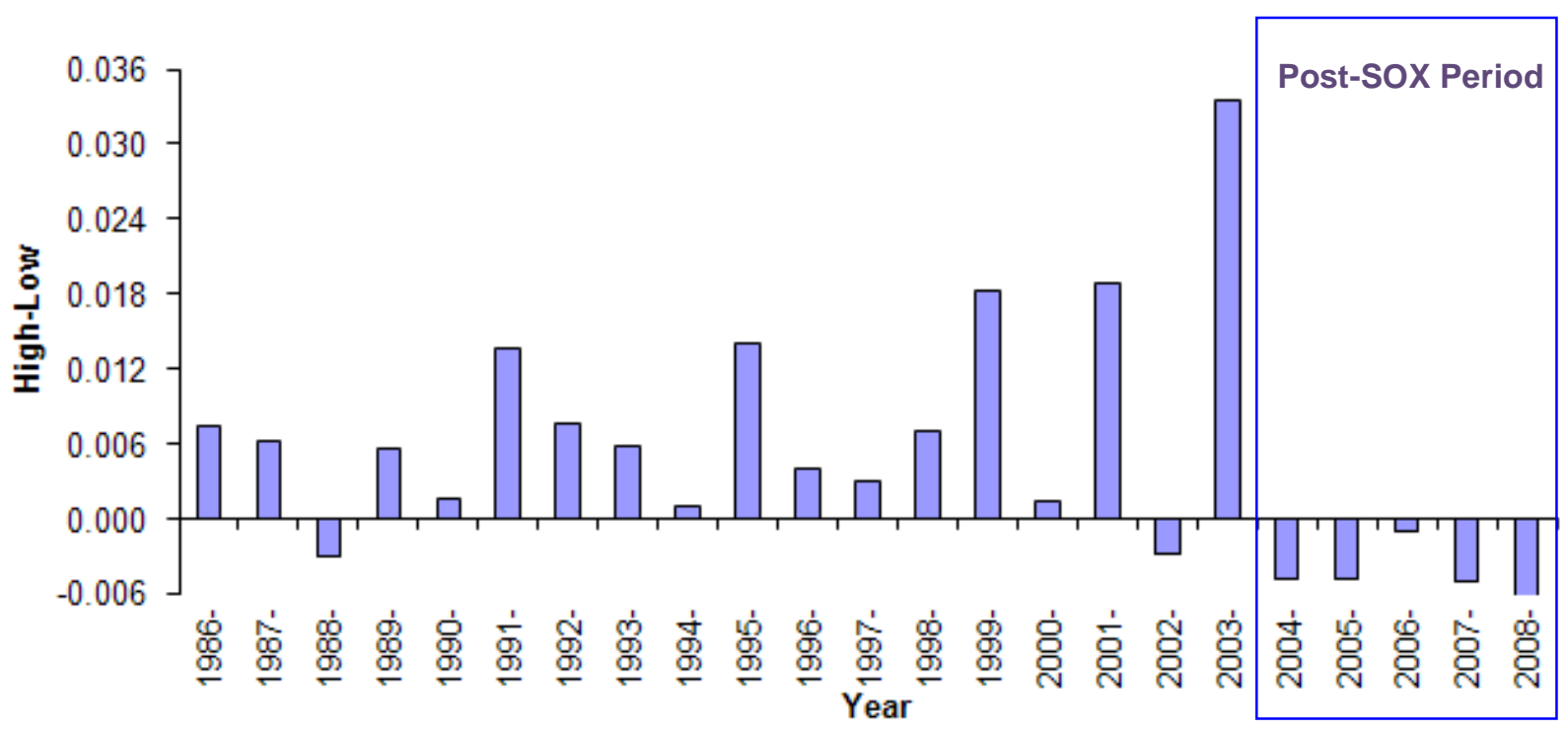

This figure presents average cash flow news adjusted excess returns for hedging portfolios sorted by conditional conservatism $(C O N)$ for each year over the period of January 1986 to December 2008. For each month, firm-month observations are assigned to five portfolios based on a firm's most recent CON (with a minimum four-month lag). Depicted are average differences in mean cash flow news adjusted excess returns between the top and bottom quintile portfolios sorted by CON. Sarbanes-Oxley Section 404 regulations were implemented in 2003-2004. 